This item was submitted to Loughborough's Research Repository by the author.

Items in Figshare are protected by copyright, with all rights reserved, unless otherwise indicated.

\title{
3D multi-nozzle system with dual drives highly potential for 3D complex scaffolds with multi-biomaterials
}

PLEASE CITE THE PUBLISHED VERSION

https://doi.org/10.1007/s12541-017-0090-8

\section{PUBLISHER}

(C) Springer Verlag (Germany)

\section{VERSION}

AM (Accepted Manuscript)

\section{PUBLISHER STATEMENT}

This work is made available according to the conditions of the Creative Commons Attribution-NonCommercialNoDerivatives 4.0 International (CC BY-NC-ND 4.0) licence. Full details of this licence are available at: https://creativecommons.org/licenses/by-nc-nd/4.0/

\section{LICENCE}

CC BY-NC-ND 4.0

\section{REPOSITORY RECORD}

Chen, Zhichao, Xianglin Zhang, Penghua Chen, Wenchao Li, Kui Zhou, Lei Shi, Kang Liu, and Changqing Liu. 2017. "3D Multi-nozzle System with Dual Drives Highly Potential for 3D Complex Scaffolds with Multibiomaterials". Loughborough University. https://hdl.handle.net/2134/24395. 


\section{International Journal of Precision Engineering and Manufacturing 3D multi-nozzle system with dual drives highly potential for 3D complex scaffolds with multi-biomaterials \\ --Manuscript Draft--}

\begin{tabular}{|c|c|}
\hline Manuscript Number: & JPEM-D-16-00704R2 \\
\hline Full Title: & $\begin{array}{l}\text { 3D multi-nozzle system with dual drives highly potential for 3D complex scaffolds with } \\
\text { multi-biomaterials }\end{array}$ \\
\hline Article Type: & Regular Paper \\
\hline Corresponding Author: & $\begin{array}{l}\text { Xianglin Zhang, Ph.D } \\
\text { Huazhong University of Science and Technology } \\
\text { Wuhan, Hubei CHINA }\end{array}$ \\
\hline \multicolumn{2}{|l|}{$\begin{array}{l}\text { Corresponding Author Secondary } \\
\text { Information: }\end{array}$} \\
\hline Corresponding Author's Institution: & Huazhong University of Science and Technology \\
\hline \multicolumn{2}{|l|}{$\begin{array}{l}\text { Corresponding Author's Secondary } \\
\text { Institution: }\end{array}$} \\
\hline First Author: & Zhichao Chen, Ph.D \\
\hline \multicolumn{2}{|l|}{ First Author Secondary Information: } \\
\hline \multirow[t]{8}{*}{ Order of Authors: } & Zhichao Chen, Ph.D \\
\hline & Xianglin Zhang, Ph.D \\
\hline & Penghua Chen, Master \\
\hline & Wenchao Li, Ph.D \\
\hline & Kui Zhou, Ph.D \\
\hline & Lei Shi, Ph.D \\
\hline & Kang Liu, Master \\
\hline & Changqing Liu, Ph.D \\
\hline \multicolumn{2}{|c|}{ Order of Authors Secondary Information: } \\
\hline \multicolumn{2}{|l|}{ Funding Information: } \\
\hline Abstract: & $\begin{array}{l}\text { Recently, additive manufacturing is one of the most focused research topics due to its } \\
\text { explosive development, especially in manufacturing engineering and medical science. } \\
\text { In order to build 3D complex scaffolds with multi-biomaterials for clinical application, a } \\
\text { new 3D multi-nozzle system with dual-mode drives, i.e. ejection and extrusion was } \\
\text { developed. In this paper, much effort was made to gain fine control of droplet and } \\
\text { excellent coordination during fabrication. Specifically, the parameters that influence the } \\
\text { size and stability of droplet most was intensively studied. Considering that the } \\
\text { biomaterials used in the future may have much difference in properties, the } \\
\text { combination of parameters was investigated to facilitate the settings for certain-sized } \\
\text { droplets, which are potentially eligible for bio-printing. The dispensing nozzles can work } \\
\text { well both in independent and convergent mode, which can be freely switched. } \\
\text { Outstanding to the most currently used 3D bio-printing techniques, this system can } \\
\text { fabricate scaffolds with multi-materials of both low viscosity (by pneumatic dispensing) } \\
\text { and high viscosity (through motor extrusion). It is highly expected that this system can } \\
\text { satisfy clinical application in the near future. }\end{array}$ \\
\hline Response to Reviewers: & $\begin{array}{l}\text { We have uploaded two separate files containing our response to the comments from } \\
\text { reviewers and editor. }\end{array}$ \\
\hline
\end{tabular}




\title{
3D multi-nozzle system with dual drives highly potential for 3D complex scaffolds with multi- biomaterials
}

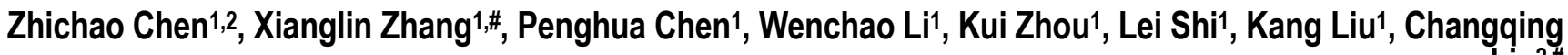 \\ Liú2,\# \\ 1 State Key Lab of Materials Processing and Die \& Mould Technology, College of Materials Science and Engineering, Huazhong University of Science and Technology, Wuhan, \\ China, 430074 \\ 2 Wolfson School of Mechanical and Manufacturing Engineering, Loughborough University, Leicestershire, United Kingdom, LE11 3TU \\ \# Corresponding Author: E-mail: hust_zxl@mail.hust.edu.cn, TEL: +86-27 87558148 (X. Zhang); C.Liu@lboro.ac.uk, TEL: +44-1509 227681 (C. Liu)
}

KEYWORDS: Additive manufacturing, Multi-nozzle system, Ejection and extrusion, Droplet control, 3D biomimetic scaffold

Recently, additive manufacturing is one of the most focused research topics due to its explosive development, especially in manufacturing engineering and medical science. In order to build $3 D$ complex scaffolds with multi-biomaterials for clinical application, a new 3D multi-nozzle system with dual-mode drives, i.e. ejection and extrusion was developed. In this paper, much effort was made to gain fine control of droplet and excellent coordination during fabrication. Specifically, the parameters that influence the size and stability of droplet most was intensively studied. Considering that the biomaterials used in the future may have much difference in properties, the combination of parameters was investigated to facilitate the settings for certainsized droplets, which are potentially eligible for bio-printing. The dispensing nozzles can work well both in independent and convergent mode, which can be freely switched. Outstanding to the most currently used 3D bio-printing techniques, this system can fabricate scaffolds with multi-materials of both low viscosity (by pneumatic dispensing) and high viscosity (through motor extrusion). It is highly expected that this system can satisfy clinical application in the near future.

\section{Introduction}

\section{NOMENCLATURE}

$\boldsymbol{\theta}=$ contact angle

$\mathbf{D}_{\mathbf{a}}=$ the actual diameter of droplet

$\mathbf{D}_{\mathbf{c}}=$ cross-sectional diameter

$\mathbf{F}_{\mathbf{c}}=$ conversion factor of $\mathrm{D}_{\mathrm{a}}$ and $\mathrm{D}_{\mathrm{c}}$

$\mathbf{R}_{\mathbf{c}}=$ cross-sectional radius $\left(=\mathrm{D}_{\mathrm{c}} / 2\right)$

$\mathbf{R}_{\mathbf{0}}=$ observed radius

$\mathbf{V}_{\mathbf{d}}=$ the actual volume of droplet

As a most promising field, additive manufacturing, especially its application in medical science (also known as three-dimensional bioprinting $^{1,2}$ ), has aroused widespread attention ${ }^{3-5}$. For instance, 3D printing technique has been one of the most focused research approaches for regeneration or repair of bone defects ${ }^{6,7}$. In bone tissue engineering, not only strength, porosity and bio-compatibility is required, highly biomimetic scaffolds could also carry growth factors ${ }^{8}$ and even functional cells ${ }^{9}$ to promote the process and effect of bone regenesis. As a result, multi-nozzle is a must in such printing system in order to support multi-materials. No wonder that the researches based on multi-nozzle systems are becoming increasingly active: hydrogel with three-tier structure for cartilage repair was successfully built using tri-nozzle system $^{10}$; Chang et al. reported a dual-head system to fabricate the functionally graded coating with titanium oxide and hydroxyapatite ${ }^{11}$; Lee et al. achieved the preparation of elastic cartilage through 3D hybrid multi-nozzle system ${ }^{12}$. For bio-printing, biomaterials such as cell suspension with grow factors, collagen etc. (usually low viscosity) are certainly desired to make the construct bioactive, which at the same time needs matrix materials (high viscosity) with sufficient mechanical strength to support biomaterials. In other words, it seems not possible for above mentioned systems to fabricate such constructs, especially biomimetic bone scaffolds.

Currently, the most used 3D technologies for biological application include fused deposition modelling (FDM ${ }^{13}$, selective laser sintering $(\mathrm{SLS})^{14}$, inkjet printing ${ }^{15}$, laser direct writing $(\mathrm{LDW})^{16}$, extrusion deposition technique ${ }^{17}$, pneumatic valve dispenser ${ }^{18}$, and so on. However, FDM and SLS require heating process at relatively high temperature, which does not apply to bioactive materials. Inkjet printing and LDW is famous for high precision, yet merely limited to low viscosity materials. Similarly, extrusion deposition is cannot deal with some biomaterials like cells, and pneumatic dispenser seems helpless to build scaffolds with high strength for hard tissues such as 
bone and teeth. Therefore, to fabricate 3D complex scaffolds with multi-materials with these techniques is challengeable.

To achieve the mentioned purpose, i.e. fabricating 3D complex scaffolds with multi-materials, PAM (pneumatics assisted microsyringe) system was introduced on the basis of motor assisted microsyringe (MAM) system ${ }^{17}$. Since the MAM system was reported in details, this paper will pay more attention to PAM system and the combination of them. Specifically, MAM is advantageous to process materials with wide range of viscosity, especially high viscosity; while PAM is right for biomaterials of low viscosity, which can finely control the dispensing of droplets by air force at high pressure and short delay.

\section{Experiments and methodology}

\subsection{PAM-MAM 3D multi-nozzle system}

Fig. 1 shows the actual image and schematic of PAM-MAM system. The pneumatic system provides the pneumatic source of positive pressure (for droplet formation) and negative pressure (to avoid salivation) with accurate regulation $( \pm 0.1 \mathrm{kPa})$. And PAM consists of three ink-jetting nozzles ( $\Phi 150 \mu \mathrm{m}$; Pusheng, China). For a single PAM, the plunger driven by air will force ink materials in micro-syringe to form droplets through the nozzle, also known as ejection. Besides, 2 of PAM nozzles (P1 and P3) can be freely switched between independent mode (gray) and convergent mode (colorful) by motors, as shown in Fig. 1(b). In convergent mode, they can focus on a point $(\mathbf{P 1 + P 2}$, $\mathbf{P 2}+\mathbf{P 3}$, or $\mathbf{P 1}+\mathbf{P 2}+\mathbf{P 3}$ ) without any interference to provide availability for multi-materials. Since it is difficult to promise synchronous formation of droplets in all nozzles, the focus point was practically set on the surface of scaffolds. Fig. 1(b) also shows the actual fabrication process; that is, the scaffold/support was initially deposited by MAM and followed by PAM jetting (drop-on-demand) during a layer. The main specification of MAM-PAM system is listed in Table 1.
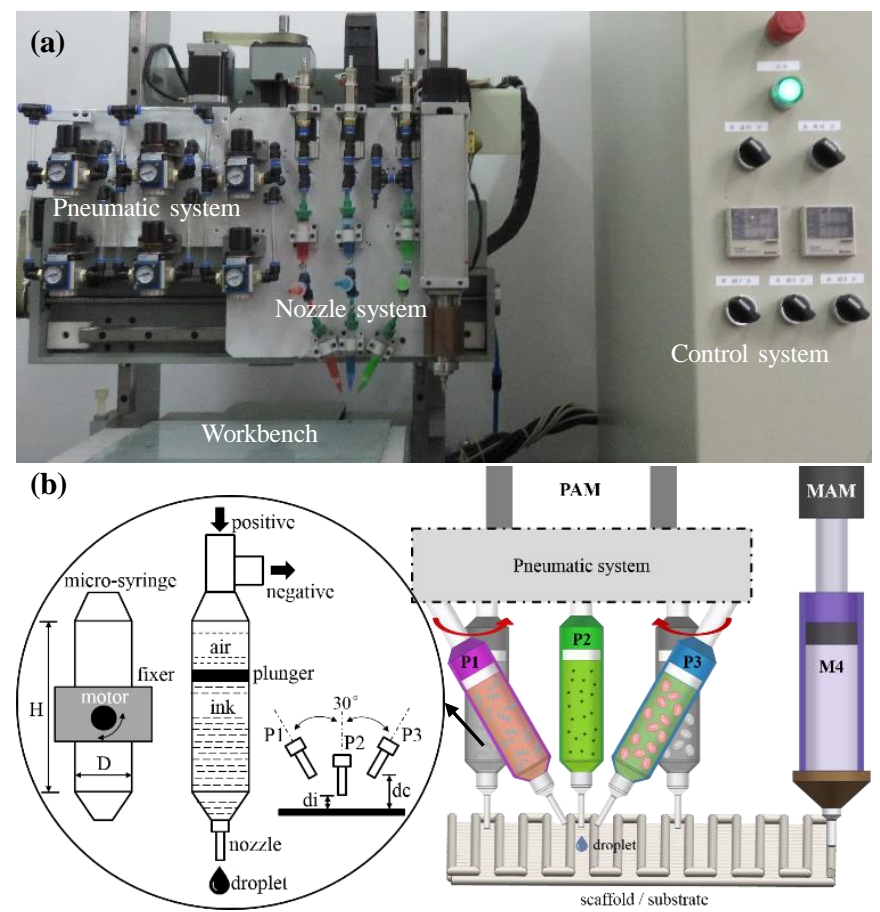

Fig. 1 The actual image (a) and schematic (b) of PAM-MAM 3D printing system (H/D: the size of PAM micro-syringe; di/dc: discharge distance in independent/convergent mode).
Table 1 Specification of MAM-PAM system

\begin{tabular}{|c|c|c|c|}
\hline МАM & Specification & PAM & Specification \\
\hline $\begin{array}{l}\text { MAM } \\
\text { system }\end{array}$ & $\begin{array}{l}\text { MAM-II, Fochif, } \\
\text { Shanghai }\end{array}$ & $\begin{array}{l}\text { PAM } \\
\text { system }\end{array}$ & Self-developed \\
\hline Positioning & $\begin{array}{l}\mathrm{X} / \mathrm{Y}: \pm 1 \mu \mathrm{m} \\
\mathrm{Z}: \pm 5 \mu \mathrm{m}\end{array}$ & Air pressure & $\begin{array}{l}\text { AP: } 0-50 \mathrm{kPa} \\
\text { NP: } 0-10 \mathrm{kPa}\end{array}$ \\
\hline Precision & $200-400 \mu \mathrm{m}$ & Precision & $\geq 300 \mu \mathrm{m}$ \\
\hline $\begin{array}{l}\text { Working } \\
\text { dimension }\end{array}$ & $\begin{array}{l}\mathrm{X} / \mathrm{Y}: 250 \mathrm{~mm} \\
\mathrm{Z}: 150 \mathrm{~mm}\end{array}$ & Micro-syringe & $\begin{array}{l}\mathrm{H}: 60 \mathrm{~mm} \\
\mathrm{D}: 10 \mathrm{~mm}\end{array}$ \\
\hline Temperature & $20-28^{\circ} \mathrm{C}$ & $\begin{array}{l}\text { Discharge } \\
\text { distance }\end{array}$ & $\begin{array}{l}\text { di: } 2.0 \mathrm{~mm} \\
\text { dc: } 7.4 \mathrm{~mm}\end{array}$ \\
\hline Delay & $<20 \mathrm{~ms}$ & Delay & $<1.5 \mathrm{~ms}$ \\
\hline
\end{tabular}

Note: AP/NP: positive/negative air pressure; temperature is controlled by air conditioner.

\subsection{Materials and parameters}

In this study, sodium alginate (SA; MW 400, Aladdin Bio-Chem Technology, China) solution with different concentration was used to assess the performance of PAM. SA solution can be easily and quickly solidified after crosslinked reaction with calcium chloride ${ }^{19-21}$ (AR$96 \%$, Aladdin), which provides great convenience to keep the shape of droplets printed by PAM. In addition, the SA solutions, concentrated from $0.00 \mathrm{wt} . \%$ (only deionized water) to $1.50 \mathrm{wt} . \%$ with an increment of $0.25 \mathrm{wt} . \%$, would be stained for the purpose of characterization if necessary. Moreover, our recent research shows that SA could even help materials of high viscosity (hydroxyapatite) maintain enough strength without sintering ${ }^{21}$, making it highly potential to build 3D scaffolds with multi-materials for bone tissue engineering.

In addition to the influence of air pressure ${ }^{22}$, the formation of droplet is also closely related to the viscosity, density and surface tension of solution $^{23}$. Therefore, the actual size of droplet during PAM ejection is hardly predictable as it is determined by numerous aerodynamics parameters ${ }^{24}$. Fortunately, according to our large amount of test, it was found that SA content, external air pressure and holding time of positive pressure mainly dominate the size of formed droplets. Given the properties of materials/solutions for PAM may vary, the adjustment of parameter sets, usually laborious and time-consuming, was a must to understand the available precision. To save time and energy, the viscosity of SA solutions was measured by a viscometer (Poiylab-RC300P, Haake Technik GmbH, Germany), and stereomicroscope (XTL240, Changfang Optical Instrument, China) was used to characterize the droplets.

\subsection{Estimation of droplet size}

To stabilize the control of droplet, it is of great significance to estimate the actual size. Gravimetry is fine for average but not for uniformity, as the mass of a droplet is usually close to the minimum scale (1mg), which would cause error. A useful method for estimation (Fig. 2) was introduced, assuming that the contact angle was equivalent for all droplets under the same condition, regardless of the difference in dimension. In this case, the contact angle can be easily calculated by large droplets with the assistance of TSView software (v7.3, Changfang) (Fig. 2). Then the actual volume can be estimated according to Eq. (I): 


$$
\left\{\begin{array}{c}
\mathrm{V}_{\mathrm{d}}=\int_{\mathrm{R}_{\mathrm{h}}}^{\mathrm{R}_{\mathrm{o}}} \pi\left(\mathrm{R}_{\mathrm{o}}{ }^{2}-\mathrm{h}^{2}\right) \cdot \mathrm{dh}(\mathrm{I}) \\
\sin \theta=\frac{\mathrm{R}_{\mathrm{c}}}{\mathrm{R}_{\mathrm{o}}} \\
R_{h}=\sqrt{R_{o}^{2}-R_{c}^{2}}
\end{array}\right.
$$

Where $\mathbf{h}$ is integral height. In view of that $\mathbf{V}_{\mathbf{d}}$ also equals $\boldsymbol{\pi} \mathbf{d}_{\mathbf{a}} \mathbf{3} / \mathbf{6}$, we can get the relationship of $\mathbf{D}_{\mathbf{a}}$ and $\mathbf{D}_{\mathbf{c}}$ through Eq. (II):

$$
D_{a}=D_{c} \cdot \sqrt[3]{\frac{2-3 \cos \theta+\cos ^{3} \theta}{4 \sin ^{3} \theta}}=F_{c} \cdot D_{c} \text { (II) }
$$

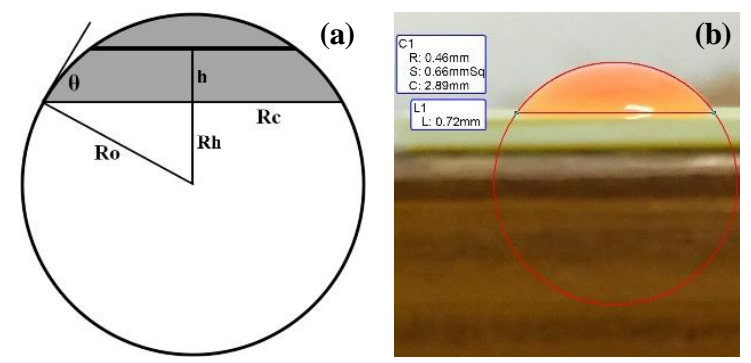

Fig. 2 Estimation method for actual size of droplet. Note for abbreviations in (b): $\mathbf{C} \mathbf{1}$ - circle, $\mathbf{R}$ - radius $\left(=\mathrm{R}_{0}\right), \mathbf{S}$ - area, $\mathbf{C}$ circumference, $\mathbf{L} 1$ - line, $\mathbf{L}$ - length $\left(=\mathrm{D}_{\mathrm{c}}\right)$.

\subsection{Fine control of droplet}

From the point of view of control flow (Fig. 3), accurate control of droplet can hardly be achieved without high response rate. Apart from control center, high response parts were used as the other elements in the flow. For instance, optoelectronic coupling relay (TLP250, Jixiang Electronics, China) can response almost immediately, and the actual responding time $(\sim 0.2 \mathrm{~ms}$ in total, including operation and release) was detected by an oscilloscope (MSOX-2004A, Agilent Technologies, USA). Besides, high performance solenoid (33 series, Mac Valves, USA) can respond to relay within $1 \mathrm{~ms}$ (energize: $0.5 \mathrm{~ms}$, de-energize: $0.2 \mathrm{~ms}$ ). In addition, the air pressure was controllable at fine precision $( \pm 0.1 \mathrm{kPa}$ ) by regulator (GR200-8, AirTac International Group, China), which greatly facilitates the adjustment of pressure. Another strategy regarding PAM nozzles is hydrophobic treatment with commercially available Teflon solution (DY18/19, Doyo Paint, China), according to the process described in user manual (Fig. 4). The nozzle was initially coated with solution A (DY18), and heated to $150^{\circ} \mathrm{C}$ (holding for $10 \mathrm{~min}$ ) at a rate of $4^{\circ} \mathrm{C} / \mathrm{min}$, followed with cooling inside the furnace (KSL-1700, Kejing Materials Technology, China) to room temperature. The treatment of solution B (DY19) is much similar: coating with B $\rightarrow$ heating to $380^{\circ} \mathrm{C}$ at $4^{\circ} \mathrm{C} / \mathrm{min} \rightarrow$ holding for $10 \mathrm{~min} \rightarrow$ cooling inside furnace.

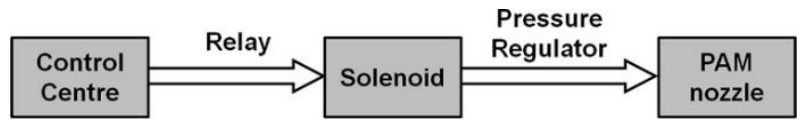

Fig. 3 Control flow of PAM system.

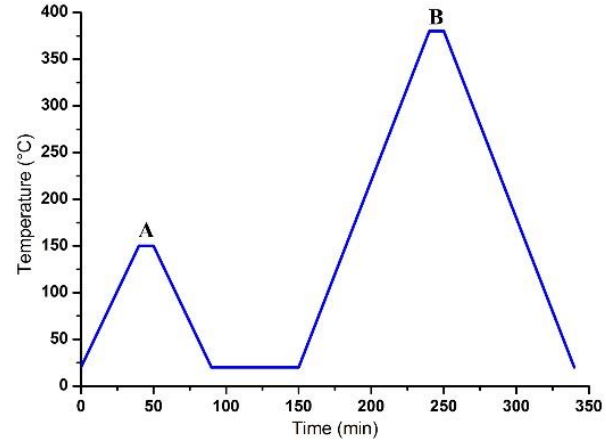

Fig. 4 Hydrophobic treatment of PAM nozzles with Teflon (A-18, B19).

In order to guarantee the stability of PAM, tests based on each SA solution with certain sets of parameters ( 20 drops for each set) was studied. The standard for stability (\%) here refers to the ability of PAM to successfully form droplets without defects (like satellite drop(s), large accumulation of bubbles in a drop, etc.). Unfortunately, it is hardly likely to ensure $100 \%$ stability due to possible turbulence by air shock at high pressure, so $90 \%$ or more was taken as high stability. Note that droplet size was neglected in practical test. Specifically, once failure in formation of a droplet during PAM jetting was found, the stability would be minused by $20 \%$ to mark such invalidity; similarly, it minus by $5 \%$ once there was any defect. Failure of formation is mainly because of insufficient air pressure, and the reason of satellite drop was explained by Klüsener ${ }^{22}$. As for bubble accumulation, it is the usually interactive result of positive air pressure (AP) and holding time (HT) of pressure. The interval of HT was set as $1.5 \mathrm{~ms}$, and AP was increased by $0.1 \mathrm{kPa}$.

\subsection{Improvement of efficiency}

Due to inertia effect, the droplets will be out of control and even severely deformed after in touch with support/substrate, at high travel speed, which may also result in inaccurate positioning. As a result, PAM nozzles would stop for a while ( $\sim 300 \mathrm{~ms})$ during jetting to make sure the velocity in travel direction was almost zero, minimizing the impact of speed. However, it would be pretty time-consuming to build 3D constructs especially in large demand of biomaterials. So it is very important to improve the efficiency of PAM jetting. Provided that the droplets were finely controlled, an easy and efficient way was to decrease the travel times of nozzle. To be more detailed, if the current layer requires PAM jetting frequently, either independent or convergent mode, larger drops with equivalent mass for less times instead of adjacent smaller ones would obviously work (Fig. 5(a)). Accordingly, it had been realized with the design of command order (automatically generated) (Fig. 5(b)). It turned out that this could save about $25 \%$ of total time overall during fabrication.

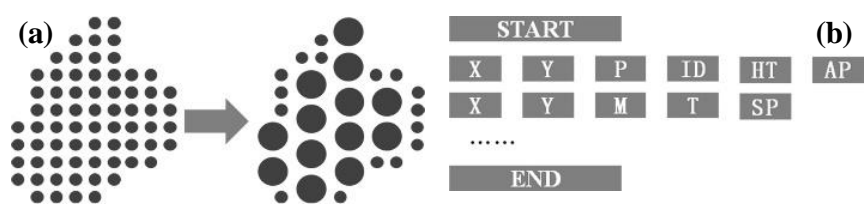

Fig. 5 Schematic of (a) efficiency improvement, and (b) command order. ' $\mathbf{X} / / \mathbf{Y}$ ' - destination position (mm); 'P' for PAM, 'M' for MAM; for PAM, 'ID' tells the active nozzles, e.g. 1 stands for 'P1', 12 for 'P1+P2' etc.; 'HT' - holding time, 'AP' -air pressure; for MAM, 'T' 
indicates the compensation of distance between MAM and last PAM nozzle(s), and 'SP' is extrusion speed.

\section{Results and discussion}

\subsection{Precision and stability}

The precision of PAM, or the minimum dimension of stable droplets, was evaluated for all SA solutions, as presented in Fig. 6, which shows the difference before and after hydrophobic treatment of PAM nozzles as well. Obviously, hydrophobic treatment indeed notably reduced the size of minimized droplet $(\geq 20 \%)$ in all solutions, indicating that hydrophobicity really contributed to improving precision. In addition, precision has close relation to viscosity of SA solutions; specifically, higher precision may be obtained with lower content of SA. Interestingly, it is found that the increase rate of precision by hydrophobicity decreases as viscosity grows. A possible explanation would be: at very low viscosity, surface tension plays the dominant role; while as viscosity increases, the impact of viscosity would be increasingly considerable. Although further study is required to approve this, the influence of viscosity on precision is definite. To make sure the precision of PAM is acceptable $(<1000 \mu \mathrm{m})^{25}$ and droplets can be easily solidified after printing, our research mainly concentrated on 0.25-1.00wt.\% SA solutions. As shown in Fig. 6, the precision in this range shows almost linear change with slight fluctuation. The stability indicates that the estimation of precision at given viscosity is possible and feasible. For instance, presumed that the viscosity of a solution was about $0.06 \mathrm{~Pa} \cdot \mathrm{s}$ (between 0.50 and $0.75 \mathrm{wt} . \%$ ), the estimated precision would be approximately $600 \mu \mathrm{m}$.

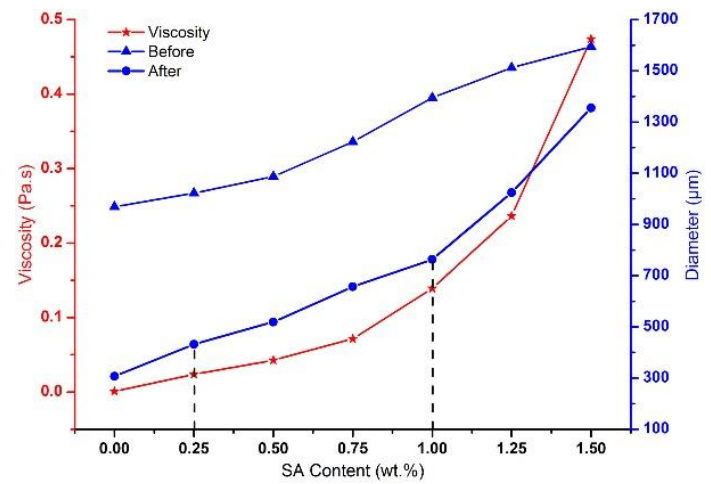

Fig. 6 The relationship of viscosity and minimum diameter before and after hydrophobic treatment.

Fig. 7(a)-(c) shows the optical images, shot at the same magnification and focal distance, of minimum-sized droplets. They were in good conditions and almost perfectly match the measure circles, with great uniformity $(\geq 98 \%)$ in terms of cross-diameter $\left(D_{c}\right)$. Fig. $7(d)$ is for evaluation of stability and positioning accuracy with 10 droplets at a distance of $2 \mathrm{~mm}$. The result is satisfying in terms of stability and uniformity, as well as the accuracy in positioning. In other words, the PAM system can be well controlled to get droplets with fine precision.
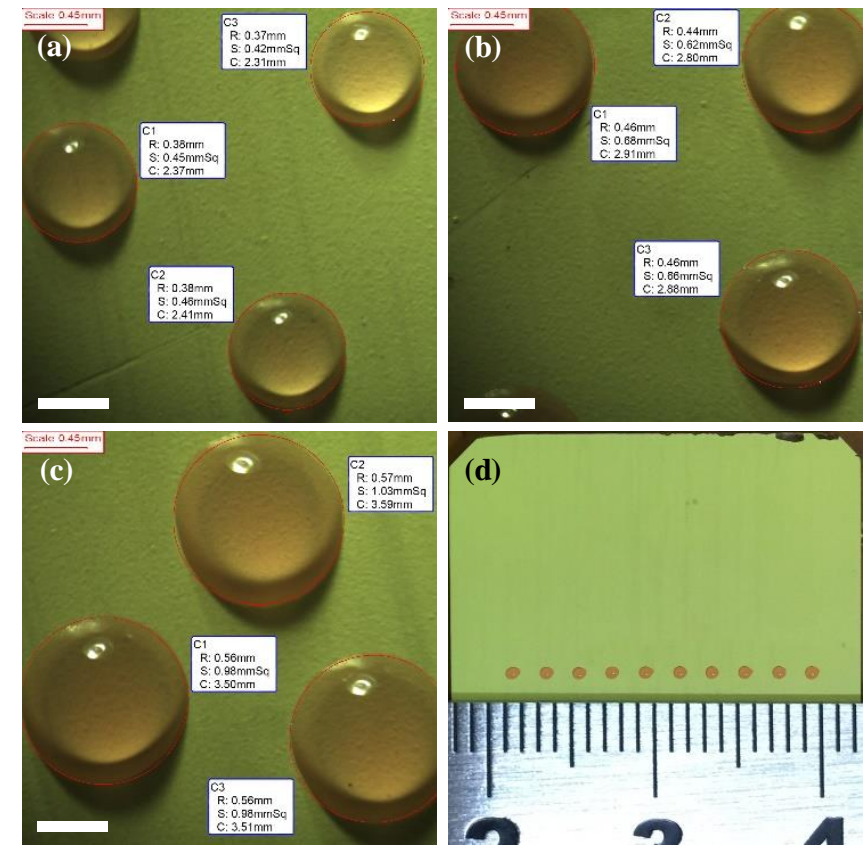

Fig. 7 Optical images of droplets: (a) $\mathrm{D}_{\text {avg }}=432 \mu \mathrm{m}(0.25 \mathrm{wt} \% \mathrm{SA}, \theta=$ $\left.50.4^{\circ}, \mathrm{F}_{\mathrm{c}}=0.574\right)$, (b) $\mathrm{D}_{\text {avg }}=519 \mu \mathrm{m}\left(0.50 \mathrm{wt} \% \mathrm{SA}, \theta=51.1^{\circ}, \mathrm{F}_{\mathrm{c}}=\right.$ $0.578)$, (c) $\mathrm{D}_{\mathrm{avg}}=657 \mu \mathrm{m}\left(0.75 \mathrm{wt} \% \mathrm{SA}, \theta=52.3^{\circ}, \mathrm{F}_{\mathrm{c}}=0.583\right)\left(\mathrm{D}_{\mathrm{avg}}\right.$ stands for average of $\mathrm{D}_{\mathrm{a}}$ ) (scale bar $\left.=500 \mu \mathrm{m}\right)$; (d) evaluation of stability ( $0.50 \mathrm{wt} \% \mathrm{SA})$ and precision in positioning.

Table 2 shows the favorable AP and HT sets for high stability ( $\geq$ 90\%) in all SA solutions. It was found that the value of AP and HT would increase as more SA was contented. This is reasonable in the light of energy conservation, since more energy would be consumed by frictional resistance, due to rising viscosity in drop formation. An sample result of stability test at $0.50 \mathrm{wt}$.\% was shown in Fig. 8. The result reveals that higher HT preferred lower AP to make ejection reliable, which is very useful for parameter adjustment in future. It is similar in other SA solutions.

Table 2 Favorable AP, NP and HT sets for high stability

\begin{tabular}{llll}
\hline SA (wt.\%) & AP $(\mathrm{kPa})$ & $\mathrm{HT}(\mathrm{ms})$ & $\mathrm{NP}(\mathrm{kPa})$ \\
\hline 0.25 & $15.0 \sim 35.0$ & $3.0,4.5$ & 3.3 \\
0.50 & $25.0 \sim 35.0$ & $3.0,4.5,6.0$ & 1.8 \\
0.75 & $25.0 \sim 40.0$ & $4.5,6.0$ & 0.7 \\
1.00 & $35.0 \sim 45.0$ & $4.5,6.0$ & Not necessary \\
\hline
\end{tabular}

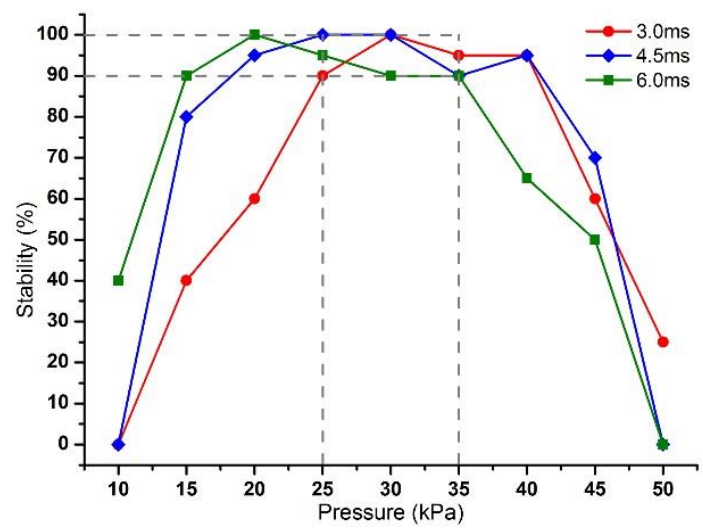

Fig. 8 The sample relationship of droplet stability with AP and HT.

As mentioned before, minimum-sized droplets are not always 
demanded in consideration of efficiency. Generally, it is very difficult to achieve the exact size by merely adjusting SA content, AP and HT, so $50 \mu \mathrm{m}$ was set as increment based on minimum size. The result of was summarized in Fig. 9 (10 drops for each set). Overall, the droplets present good uniformity ( $\geq 95 \%$ ), despite that the deviation actually shows rising trend when SA content increases. The parameter sets for every dimension were on the basis of Table 2 to ensure stability. A database according to this result had been set up to accelerate the adjustment of parameters. For a solution with given viscosity, the database can offer reference for the suitable set of HT, AP and NP to achieve desired size of droplets with great convenience. For example, if $600 \mu \mathrm{m}$ was wanted from $0.40 \mathrm{wt} . \%$ SA solution, the suggested set of HT, AP and NP would be $3.0 \mathrm{~ms}, 27.8-34.4 \mathrm{kPa}$, and $1.8-3.3 \mathrm{kPa}$ respectively. In addition, for droplets smaller than $\mathrm{S} \Phi 650 \mu \mathrm{m}, 3.0 \mathrm{~ms}$ is enough for HT, and $35.0 \mathrm{kPa}$ may be the up limit of AP. Similarly, for those within S $\Phi 700-800 \mu \mathrm{m}$, HT should better be $4.5 \mathrm{~ms}$, and AP must be higher than $25.0 \mathrm{kPa}$. The list goes on like this. All in all, the amount of work to adjust parameter sets for new materials/solutions will be greatly reduced.

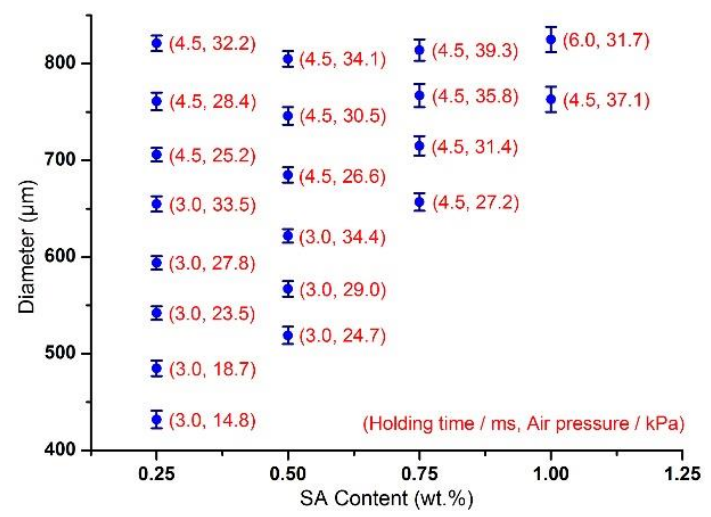

Fig. 9 Parameter sets for certain sized droplets.

\subsection{Coordination and synchronization}

The key challenge for PAM-MAM (multi-nozzles) system lies in their coordination and synchronization, especially in independent and convergent mode. Therefore, experiments using $0.50 \mathrm{wt} . \%$ SA solution for PAM jetting were carefully designed to confirm this. The dot matrix in Fig. 10(a) was primarily to evaluate the repeatability and accuracy of positioning, in which the droplets could manage to keep good shape and maintain accurate location. On the other hand, "HUST" in Fig. 10 (b) is another expressive example. "H" and "S" were printed by PAM at highest precision $\left(\mathrm{D}_{\mathrm{a}}=487 \pm 26 \mu \mathrm{m}\right)$ in independent mode; while "T" was formed in convergent mode, reasonably resulting in larger and less regular droplets $\left(\mathrm{D}_{\mathrm{a}}=676 \pm 53 \mu \mathrm{m}\right)$ due to impaction and adhesion of droplets. It shows that the precision both in size and positioning is acceptable, greatly owing to the set of convergent focus on substrate, short pause and low frequency during jetting. Although the satellite drops caused by collision were unavoidable, it affected the precision only a bit $(<5 \mu \mathrm{m})$. It is worth mentioning that the droplets assembling "H" were actually blue, which yet looks green due to color overlay (blue plus yellow will be green); similarly, "S" appears orange instead of red, and "T" is dark rather than purple. In summary, PAMMAM could keep fine precision as well as good coordination and synchronization during work, providing the essential foundation for fabricating 3D complex scaffolds with multi-biomaterials.
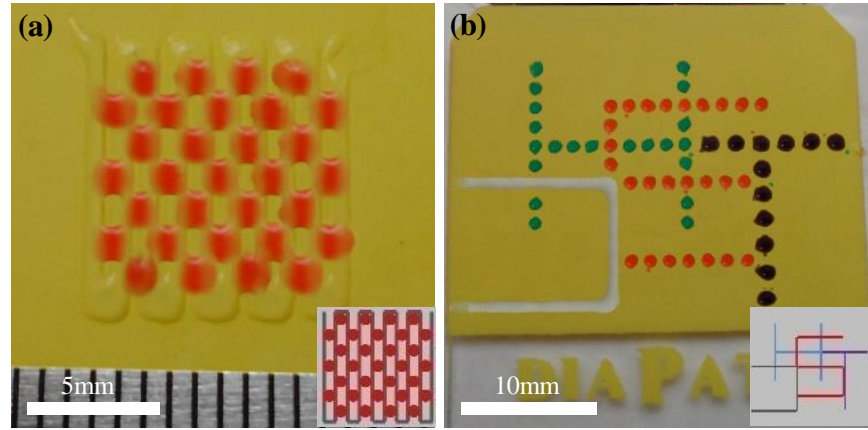

Fig. 10 Patterns for evaluation of coordination: (a) dot matrix, and (b) "HUST" ('H' by $\mathbf{P 1}$, 'U' by $\mathbf{M 4}$, 'S' by $\mathbf{P 3}$, and 'T' by $\mathbf{P 1 + P 3}$ ). The figure in right corner is the original design of each pattern.

\subsection{Potential application}

In our recent research, biomimetic scaffolds with multi-biomaterials (e.g. collagen) for repair of the cranium defect (rabbit) showed absolute advantages to normal scaffolds made by MAM. The result has been processed for publication elsewhere. Fig. 11 shows the 3D model with SA solution (0.5wt.\% for PAM, and $10.0 \mathrm{wt} . \%$ for MAM) for demonstration; while actually it was composed of biomaterials (jetting by PAM) and matrix (extrusion with MAM) with SA as solidification agent in practice. The sample has 6 layers in total: the 1st and 6th layer in transparency stands for antimicrobial materials; and the 2nd and 5th layer in green with porous structures were designed for collagen filling; the middle two layers with dual red lines which consists of droplets represent biological factors. It is worth mentioning that the desired size of droplets for this scaffold should be about $500 \mu \mathrm{m}$; however, to improve efficiency, the jetting strategy in Fig. 5(a) was adopted, resulting in two lines rather than dot matrixes. After quick solidification (cross-linking reaction) with calcium chloride solution, the droplets were able to keep original shape, and could be well supported by porous scaffold due to good strength, shown in Fig. 11(b). It indicates that PAM-MAM is competent to make $3 \mathrm{D}$ biomimetic scaffolds in terms of materials and structures, exhibiting great potential to tissue engineering.
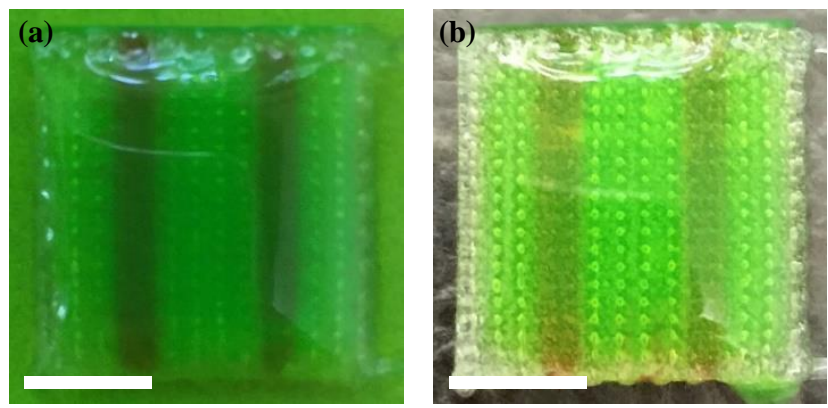

Fig. 11 3D model of biomimetic scaffolds for repair of rabbit cranium defects, (a) before and (b) $12 \mathrm{~h}$ after solidification. Scale bar $=5 \mathrm{~mm}$.

\section{Conclusions}

In this study, a newly combined multi-nozzle system based on MAM and PAM was introduced. The influence of AP, HT and SA content on droplet size and stability was investigated in details. The results show that droplets by PAM jetting can be finely controlled with good precision $(\sim \mathrm{S} \Phi 430 \mu \mathrm{m})$ and high stability $(\geq 90 \%)$. The parameter sets 
for certain size can be easily obtained with the assistance of our database, regardless of the various properties of materials for PAM. The most of all, this system can deal with materials both of low and high viscosity with satisfying coordination and synchronization, making it highly potential to fabricate $3 \mathrm{D}$ complex scaffolds with multi-biomaterials and sufficient strength for tissue engineering. Thus it is highly expected that this research could provide practical and technical reference for the development of organ printing.

\section{ACKNOWLEDGEMENT}

This study was fully supported by the project from State Key Lab of Materials Processing and Die \& Mould Technology (No.2014-5), and partially funded by programmes from Science and Technology Support Program of Jiangsu (No.BE2013057). The authors would also like to acknowledge the Analytical and Testing Centre of Huazhong University of Science and Technology for rheology test of SA solution.

\section{REFERENCES}

1). Ringeisen, B. R., Spargo, B. J. and Wu, P. K., "Cell and organ printing," Springer Sci. \& Bus. Media, 2010.

2). Yoo, D. J., "Recent trends and challenges in computer-aided design of additive manufacturing-based biomimetic scaffolds and bioartificial organs,” Int. J. Precis. Eng. Man., Vol. 15, No. 10, pp. 2205-2217, 2014. 3). Gibson, I., Rosen, D.W. and Stucker, B., "Additive manufacturing technologies," New York: Springer, Vol. 238, 2010.

4). Wong, K. V. and Hernandez, A., "A review of additive manufacturing,” ISRN Mech. Eng., Vol. 2012, 2012.

5). Guo, N. and Leu, M. C., "Additive manufacturing: technology, applications and research needs," Front. Mech. Eng., Vol. 8, No. 3, pp. 215-243, 2013.

6). Bose, S., Vahabzadeh, S. and Bandyopadhyay, A., "Bone tissue engineering using 3D printing," Mater. Today, Vol. 16, No. 12, pp. 496504, 2013.

7). Chern, M. J., Yang, L. Y., Shen, Y. K. and Hung, J. H., "3D scaffold with PCL combined biomedical ceramic materials for bone tissue regeneration,” Int. J. Precis. Eng. Man., Vol. 14, No. 12, pp. 2201-2207, 2013.

8). Pati, F., Song, T. H., Rijal, G., Jang, J., Kim, S. W. and Cho, D. W., "Ornamenting 3D printed scaffolds with cell-laid extracellular matrix for bone tissue regeneration," Biomaterials, Vol. 37, pp. 230-241, 2015. 9). Suárez-González, D., Lee, J. S., Diggs, A., Lu, Y., Nemke, B., Markel, M., Hollister, S. J. and Murphy, W. L., "Controlled multiple growth factor delivery from bone tissue engineering scaffolds via designed affinity," Tissue Eng. Part A, Vol. 20, No. 15-16, pp. 20772087, 2013.

10). Klein, T. J., Rizzi, S. C., Reichert, J. C., Georgi, N., Malda, J., Schuurman, W., Crawford, R. W. and Hutmacher, D. W., "Strategies for zonal cartilage repair using hydrogels," Macromol. Biosci., Vol. 9, No. 11, pp. 1049-1058, 2009.

11). Chang, L., Thian, E., Sun, J., Fuh, J., Hong, G., Wong, Y. and Wang, W., "Fabrication of functionally graded hydroxyapatite / titanium oxide coating via drop-on-demand technique," Nano LIFE, Vol. 2, No. 01, pp. 1250009, 2012.

12). Lee, J. S., Hong, J. M., Jung, J. W., Shim, J. H., Oh, J. H. and Cho, D. W., "3D printing of composite tissue with complex shape applied to ear regeneration,” Biofabrication, Vol. 6, No. 2, pp. 024103, 2014.
13). Kalita, S. J., Bose, S., Hosick, H. L. and Bandyopadhyay, A., "Development of controlled porosity polymer-ceramic composite scaffolds via fused deposition modeling," Mater. Sci. Eng. C, Vol. 23, No. 5, pp. 611-620, 2003.

14). Williams, J. M., Adewunmi, A., Schek, R. M., Flanagan, C. L., Krebsbach, P. H., Feinberg, S. E., Hollister, S. J. and Das, S., "Bone tissue engineering using polycaprolactone scaffolds fabricated via selective laser sintering," Biomaterials, Vol. 26, No. 23, pp. 4817-4827, 2005.

15). Singh, M., Haverinen, H. M., Dhagat, P. and Jabbour, G. E., "Inkjet printing - process and its applications," Adv. Mater., Vol. 22, No. 6, pp. 673-685, 2010.

16). Schiele, N. R., Corr, D. T., Huang, Y., Raof, N. A., Xie, Y. and Chrisey, D. B., "Laser-based direct-write techniques for cell printing," Biofabrication, Vol. 2, No. 3, pp. 032001, 2010.

17). Huang, W., Zhang, X., Wu, Q. and Wu, B., "Fabrication of HA/ $\beta$ TCP scaffolds based on micro-syringe extrusion system," Rapid Prototyping J., Vol. 19, No. 5, pp. 319-326, 2013.

18). Ren, X., Zhang, Q., Liu, K., Li, H.-L. and Zhou, J. G., "Modeling of pneumatic valve dispenser for printing viscous biomaterials in additive manufacturing," Rapid Prototyping J., Vol. 20, No. 6, pp. 434443, 2014.

19). Blandino, A., Macias, M. and Cantero, D., "Formation of calcium alginate gel capsules: influence of sodium alginate and $\mathrm{CaCl} 2$ concentration on gelation kinetics," J. Biosci. and Bioeng., Vol. 88, No. 6, pp. 686-689, 1999.

20). Zactiti, E. M. and Kieckbusch, T. G., "Release of potassium sorbate from active films of sodium alginate crosslinked with calcium chloride," Packag. Technol. Sci., Vol. 22, pp. 349-358, 2009.

21). Zhou, K., Zhang, X., Chen, Z., Shi, L. and Li, W., "Preparation and characterization of hydroxyapatite-sodium alginate scaffolds by extrusion freeforming," Ceram. Int., Vol. 41, No. 10, pp. 14029-14034, 2015.

22). Klüsener, O., "The injection process in compressorless diesel engines," VDI Z, Vol. 77, No. 7, 1933.

23). Ohnesorge, W. V., "Formation of drops by nozzles and the breakup of liquid jets," Z. Angew. Math. Mech., Vol. 16, No. 4, pp. 355-358, 1936.

24). Lefebvre, A., "Atomization and sprays,” CRC press, 1988.

25). Yeong, W. Y., Chua, C. K., Leong, K. F. and Chandrasekaran, M., "Rapid prototyping in tissue engineering: challenges and potential," Trends Biotechnol., Vol. 22, No. 12, pp. 643-652, 2004. 


\section{Dear Editor and Reviewers,}

Many thanks to you for the careful attention of our paper. We have corrected the manuscript carefully to our best knowledge according to the comments. And we also revised the manuscript in addition to your comments to make some of the expressions more clear. All of our revisions were marked with red in track mode, which is attached as a PDF file (detailed revision.pdf).

Here it lists the reviewers' comments and our response (point by point):

Comments \#1: Please fill out this manuscript by partitioning Introduction and Fig. 1(PAM-MAM 3D printing system).

Our response: The introduction of PAM-MAM system has been moved to Section 2.1, and the other sub-sections in "Experiments and methodology" were also made some changes. Please find the revision details in the PDF file.

Comments \#2: What is the standard (size or volume) of Micro-syringe used at PAMMAM $3 D$ printing system? Please fill out on this manuscript.

Comments \#3: Detailed contents about PAM-MAM 3D printing system are required. (ex.: working dimension, pressure and temperature controllers, etc.) The manuscript is not properly made out.

Our response: We are really sorry about the incomplete specification of PAM-MAM system. We have tried our best to give as many details as possible in updated Fig. 1(b) and Table 1.

Comments \#4: There is Piston into syringe on Fig. 1. What is mean of piston? Is it Plunger to use the transmission of air pressure or compression of fluid?

Our response: Yes, it is the plunger to use the transmission of air pressure or compression of fluid. We have revised this mistake in Fig. 1(b).

Comments \#5: To rotate the P1 and P2 syringes, what did you use for the rotation tool? Please fill out on this manuscript.

Our response: We are sorry that we didn't give enough details about rotation of PAM nozzles. Actually, only P1 and P3 will be rotated by motors in convergent mode. The relevant changes can be found in Line 6 in Section 2.1. The "fixer" that grips PAM micro-syringe is controlled by a motor, which performs the rotation automatically for independent or convergent mode according to our demands.

Comments \#6: In introduction, please refer material characteristics and references about used sodium alginate solution.

Our response: The main characteristics of sodium alginate solution is that it can be easily and quickly solidified after crosslinked reaction with calcium chloride (Ref. 1921). The details regarding to characteristics and references could be found in Section 2.2 . 
Comments \#7: Please write "Table 1, 2" instead of "Table I, II".

Our response: Really sorry about such mistakes. The expressions about "Table 1 and 2 " have been revised.

Comments \#8: Clearly write the scale bar mark of Fig. 7, please.

Our response: It is true that the scale bar marks in Fig. 7(a), (b) and (c) are not very clear. We apologize for unawareness of this problem. Additional scale bar marks were provided on the basis of original ones. Since the ruler in Fig. 7(d) can serve as a scale bar mark, no change was made to this figure.

Comments \#9: There's no Fig. 7(b).

Our response: The figure on top-right corner is Fig. 7(b), not Fig. 7(c).

Comments \#10: Please express the scale bar mark on Fig. $10($ a) and Fig. 11(b).

Our response: Sorry again for the problem of scale bar mark. We used the ruler in Fig. 10(a) as the scale bar mark. For Fig. 11(b), the scale bar mark is almost the same, so we didn't provide it. It is really our unprofessional solutions for Fig. 10 (a) and Fig. 11(b) that result in such mistakes. The scale bar has been clearly marked in the two figures.

Comments \#11: What is the discharge distance between nozzle tip and plate? Please fill out on this manuscript.

Our response: The discharge distance between nozzle tip and scaffold/substrate (shown in Fig. 1(b)) in both modes (di and dc) was listed in Table 1, where dc is larger than di because of rotation.

Comments \#12: What is the test standard of Stability (\%) on Fig. 8? Please fill out on this manuscript.

Our response: The standard for stability $(\%)$ here refers to the ability of PAM to successfully form droplets without defects (like satellite drop(s), large accumulation of bubbles in a drop, etc.). The standard can be found in Paragraph 2 in Section 2.4.

Comments \#13: Would you check porosity of scaffold after solidification? There doesn't seem to be any pore structure about scaffold. Please fill out on this manuscript.

Our response: Actually the porous structure of biomimetic scaffold in Fig. 11 was formed by MAM (shown in the figure (a) below). Some of the pore structure could still be recognized in Fig. 11(b), marked with red circle in figure (b) below. However, most of the pores will be filled with droplets (usually biomaterials, but it was SA solutions in Fig. 11) by PAM to improve the bioactivity of scaffolds. For instance, the 1st and 6th layer in Fig. 11(b) will be fully filled with antimicrobial materials to enhance the antimicrobial performance; 2nd and 5th partially filled with collagen, resulting in some recognizable pores; 3rd and 4th layer for biological factors. So we didn't measure the porosity of scaffold after solidification. It is still possible to estimate the bulk porosity through gravimetry method, because the concentration of SA (either $0.5 \mathrm{wt} . \%$ or $10 \mathrm{wt} . \%$ ) would not have much influence on the density of SA solution even after solidification. 

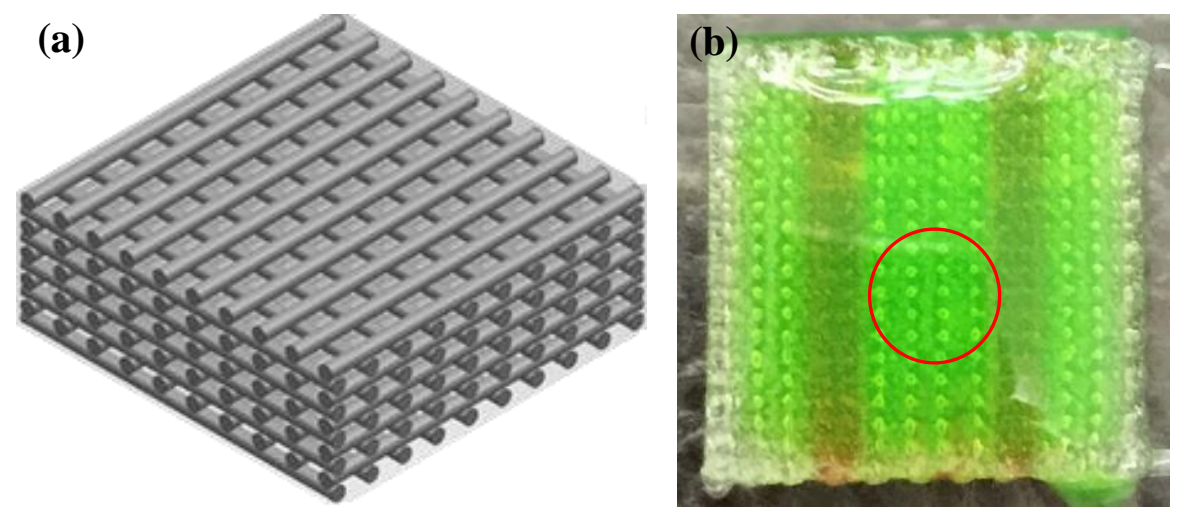

Gravimetry method: $\quad \mathrm{P} \%=\left(1-\frac{\rho_{s}}{\rho_{m}}\right) \times 100 \%(\mathrm{Hu}, \mathrm{Y}$., Grainger, D. W., Winn, S. R. and Hollinger J. O., "Fabrication of poly ( $\alpha$-hydroxy acid) foam scaffolds using multiple solvent systems," J. Biomed. Mater. Res., Vol. 59, No. 3, pp. 563-572, 2002.)

Where $\rho_{\mathrm{s}}$ stands for the density of scaffold ( $\rho_{\mathrm{s}}=$ the weight of scaffold/the bulk volume), and $\rho_{\mathrm{m}}$ is the density of materials which form scaffolds.

Comments \#14: In reference, please write contents according to form of JPEM template. Write as the examples given bellows.

Our response: All of the references, which were managed by EndNote, have been manually edited according to form of JPEM template.

We hope our response can answer the reviewers' comments. Many thanks again for your attention.

Yours sincerely,

Dr. Xianglin Zhang

Jan 19, 2017 


\title{
3D multi-nozzle system with dual drives highly potential for 3D complex scaffolds with multi- biomaterials
}

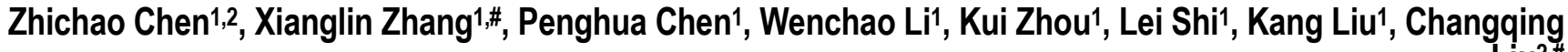 \\ Liu2,\# \\ 1 State Key Lab of Materials Processing and Die \& Mould Technology, College of Materials Science and Engineering, Huazhong University of Science and Technology, Wuhan, \\ China, 430074 \\ 2 Wolfson School of Mechanical and Manufacturing Engineering, Loughborough University Leicestershire, United Kingdom, LE11 3TU \\ \# Corresponding Author: E-mail: hust_zxl@mail.hust.edu.cn, TEL: +86-27 87558148 (X. Zhang); C.Liu@lboro.ac.uk, TEL: +44-1509 227681 (C. Liu)
}

KEYWORDS: Additive manufacturing, Multi-nozzle system, Ejection and extrusion, Droplet control, 3D biomimetic scaffold

\begin{abstract}
Recently, additive manufacturing is one of the most focused research topics due to its explosive development, especially in manufacturing engineering and medical science. In order to build $3 D$ complex scaffolds with multi-biomaterials for clinical application, a new 3D multi-nozzle system with dual-mode drives, i.e. ejection and extrusion was developed. In this paper, much effort was made to gain fine control of droplet and excellent coordination during fabrication. Specifically, the parameters that influence the size and stability of droplet most was intensively studied. Considering that the biomaterials used in the future may have much difference in properties, the combination of parameters was investigated to facilitate the settings for certainsized droplets, which are potentially eligible for bio-printing. The dispensing nozzles can work well both in independent and convergent mode, which can be freely switched. Outstanding to the most currently used 3D bio-printing techniques, this system can fabricate scaffolds with multi-materials of both low viscosity (by pneumatic dispensing) and high viscosity (through motor extrusion). It is highly expected that this system can satisfy clinical application in the near future.
\end{abstract}

\section{Introduction}

As a most promising field, additive manufacturing, especially its application in medical science (also known as three-dimensional bioprinting $^{1,2}$ ), has aroused widespread attention ${ }^{3-5}$. For instance, 3D printing technique has been one of the most focused research approaches for regeneration or repair of bone defects ${ }^{6,7}$. In bone tissue engineering, not only strength, porosity and bio-compatibility is required, highly biomimetic scaffolds could also carry growth factors ${ }^{8}$ and even functional cells ${ }^{9}$ to promote the process and effect of bone regenesis. As a result, multi-nozzle is a must in such printing system in order to support multi-materials. No wonder that the researches based on multi-nozzle systems are becoming increasingly active: hydrogel with three-tier structure for cartilage repair was successfully built using tri-nozzle system ${ }^{10}$; Chang et al. reported a dual-head system to fabricate the functionally graded coating with titanium oxide and hydroxyapatite $^{11}$; Lee et al. achieved the preparation of elastic cartilage through 3D hybrid multi-nozzle system ${ }^{12}$. For bio-printing, biomaterials such as cell suspension with grow factors, collagen etc. (usually low viscosity) are certainly desired to make the construct bioactive, which at the same time needs matrix materials (high viscosity) with sufficient mechanical strength to support biomaterials. In other words, it seems not possible for above mentioned systems to fabricate such constructs, especially biomimetic bone scaffolds.

Currently, the most used 3D technologies for biological application include fused deposition modelling $(\mathrm{FDM})^{13}$, selective laser sintering $(\mathrm{SLS})^{14}$, inkjet printing ${ }^{15}$, laser direct writing (LDW) $)^{16}$, extrusion deposition technique ${ }^{17}$, pneumatic valve dispenser ${ }^{18}$, and so on. However, FDM and SLS require heating process at relatively high temperature, which does not apply to bioactive materials. Inkjet printing and LDW is famous for high precision, yet merely limited to low viscosity materials. Similarly, extrusion deposition is cannot deal with some biomaterials like cells, and pneumatic dispenser seems helpless to build scaffolds with high strength for hard tissues such as 
bone and teeth. Therefore, to fabricate 3D complex scaffolds with multi-materials with these techniques is challengeable.

To achieve the mentioned purpose, i.e. fabricating 3D complex scaffolds with multi-materials, PAM (pneumatics assisted microsyringe) system was introduced on the basis of motor assisted microsyringe (MAM) system ${ }^{17}$. Since the MAM system was reported in details, this paper will pay more attention to PAM system and the combination of them. Specifically, MAM is advantageous to process materials with wide range of viscosity, especially high viscosity; while PAM is right for biomaterials of low viscosity, which can finely control the dispensing of droplets by air force at high pressure and short delay.

Fig. 1 shows the actual image and schematic of PAM-MAM system. The pneumatic system provides the pneumatic source of positive pressure (for droplet formation) and negative pressure (to avoid salivation) with accurate regulation $( \pm 0.1 \mathrm{kPa})$. And PAM consists of three ink jetting nozzles ( $\Phi 150 \mu \mathrm{m}$; Pusheng, China). For a single PAM, the piston driven by air will force liquid materials in micro-syringe to form droplets through the nozzle, also known as ejection. In addition, PAM nozzles can be freely switched between independent mode (gray) and convergent mode (colorful), as shown in Fig. 1(b). In convergent mode, they can focus on a point $(\mathbf{P} 1+\mathbf{P} 2, \mathbf{P} 2+\mathbf{P} 3$, or $\mathbf{P 1}+\mathbf{P} 2+\mathbf{P} 3)$ without any interference to provide availability for multi materials. Since it is difficult to promise synchronous formation of droplets in all nozzles, the focus point was practically set on the surface of scaffolds. Fig. 1(b) also shows the actual fabrication process; that is, the seaffeld/support was initially deposited by MAM and followed by PAM jetting (drop-on-demand) during a layer. The main specification Of MAM PAM system is listed in Table I.

Fig. 1 The actul image (a) and-schematic (b) of PAM MAM 3D printing system.

Table I Specification of MAM-PAM system

\section{Experiments and methodology}

\subsection{PAM-MAM 3D multi-nozzle system}

Fig. 1 shows the actual image and schematic of PAM-MAM system. The pneumatic system provides the pneumatic source of positive pressure (for droplet formation) and negative pressure (to avoid salivation) with accurate regulation $( \pm 0.1 \mathrm{kPa})$. And PAM consists of three ink-jetting nozzles $(\Phi 150 \mu \mathrm{m}$; Pusheng, China). For a single PAM, the plunger driven by air will force ink materials in micro-syringe to form droplets through the nozzle, also known as ejection. Besides, 2 of PAM nozzles (P1 and P3) can be freely switched between independent mode (gray) and convergent mode (colorful) by motors, as shown in Fig. 1(b). In convergent mode, they can focus on a point $(\mathbf{P 1}+\mathbf{P 2}$, $\underline{\mathbf{P 2}+\mathbf{P 3} \text {, or } \mathbf{P 1}+\mathbf{P 2}+\mathbf{P} 3 \text { ) without any interference to provide availability }}$ for multi-materials. Since it is difficult to promise synchronous formation of droplets in all nozzles, the focus point was practically set on the surface of scaffolds. Fig. 1(b) also shows the actual fabrication process; that is, the scaffold/support was initially deposited by MAM and followed by PAM jetting (drop-on-demand) during a layer. The main specification of MAM-PAM system is listed in Table 1.
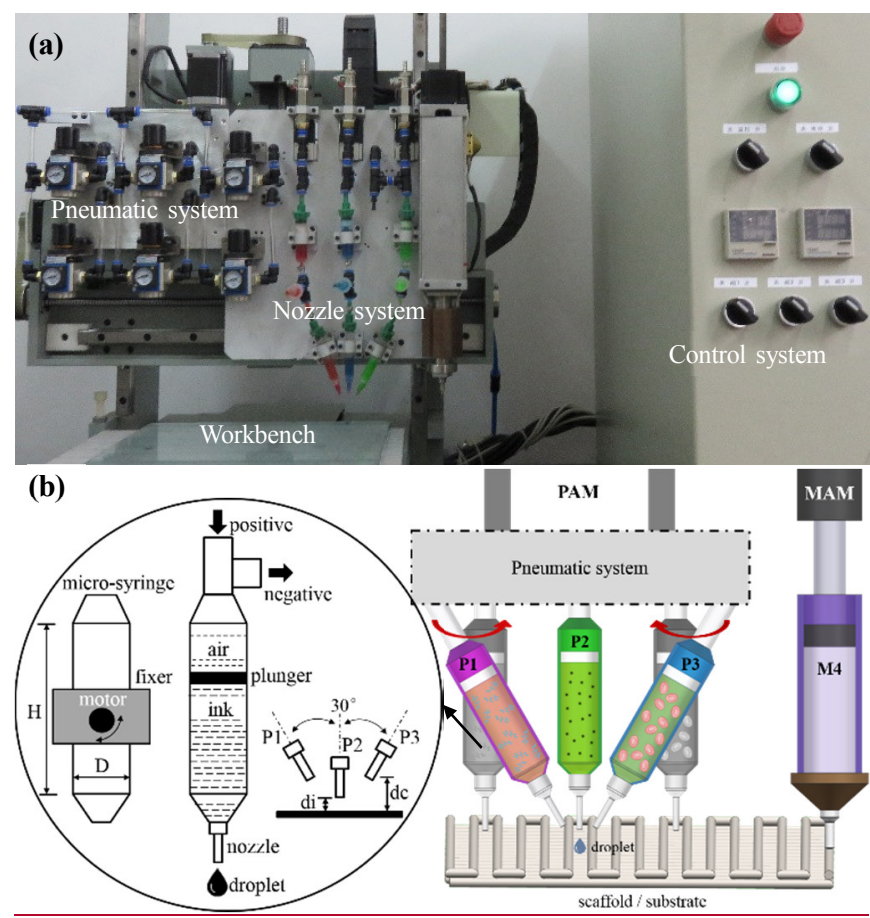

Fig. 1 The actual image (a) and schematic (b) of PAM-MAM 3D printing system (H/D: the size of PAM micro-syringe; di/dc: discharge distance in independent/convergent mode).

Table 1 Specification of MAM-PAM system

\begin{tabular}{|c|c|c|c|}
\hline MAM & Specification & PAM & Specification \\
\hline$\frac{\text { MAM }}{\text { system }}$ & $\frac{\text { MAM-II, Fochif, }}{\text { Shanghai }}$ & $\frac{\text { PAM }}{\text { system }}$ & Self-developed \\
\hline Positioning & $\frac{\mathrm{X} / \mathrm{Y}: \pm 1 \mu \mathrm{m}}{\underline{\mathrm{Z}: \pm 5 \mu \mathrm{m}}}$ & Air pressure & $\begin{array}{l}\text { AP: } 0-50 \mathrm{kPa} \\
\text { NP: } 0-10 \mathrm{kPa}\end{array}$ \\
\hline$\underline{\text { Precision }}$ & $200-400 \mu \mathrm{m}$ & $\underline{\text { Precision }}$ & $\geqq 300 \mu \mathrm{m}$ \\
\hline$\frac{\text { Working }}{\text { dimension }}$ & $\frac{\mathrm{X} / \mathrm{Y}: 250 \mathrm{~mm}}{\mathrm{Z}: 150 \mathrm{~mm}}$ & Micro-syringe & $\frac{\mathrm{H}: 60 \mathrm{~mm}}{\mathrm{D}: 10 \mathrm{~mm}}$ \\
\hline Temperature & $20-28^{\circ} \mathrm{C}$ & $\frac{\text { Discharge }}{\text { distance }}$ & $\frac{\text { di: } 2.0 \mathrm{~mm}}{\text { dc: } 7.4 \mathrm{~mm}}$ \\
\hline Delay & $\leq 20 \mathrm{~ms}$ & $\underline{\text { Delay }}$ & $\leq 1.5 \mathrm{~ms}$ \\
\hline
\end{tabular}

Note: AP/NP: positive/negative air pressure; temperature is controlled by air conditioner.

\subsection{Materials and parameters}

In this study, sodium alginate (SA; MW 400, Aladdin Bio-Chem Technology, China) solution with different concentration was used to assess the performance of PAM.; SA solution can be easily and quickly solidified after crosslinked reaction with calcium chloride ${ }^{19-21}$ (AR$96 \%$, Aladdin), which provides because of great convenience to keep the shape of SAdroplets printed by PAM. owing to quick solidification with calcium chloride (AR-96\%, Aladdin) after cross-linking reaction ${ }^{19}-$ In addition, Tthe SA solutions, concentrated from $0.00 \mathrm{wt} . \%$ (only deionized water) to $1.50 \mathrm{wt} . \%$ with an increment of $0.25 \mathrm{wt} . \%$, would be stained for the purpose of characterization if necessary. Moreover, our recent research shows that SA could even help materials of high viscosity (hydroxyapatite) maintain enough strength without sintering ${ }^{212 \theta}$, making it highly potential to build $3 \mathrm{D}$ scaffolds with multi-materials for bone tissue engineering.

In addition to the influence of air pressure ${ }^{22+}$, the formation of 
droplet is also closely related to the viscosity, density and surface tension of solution ${ }^{23 z}$. Therefore, the actual size of droplet during PAM ejection is hardly predictable as it is determined by numerous aerodynamics parameters ${ }^{243}$. Fortunately, according to our large amount of test, it was found that SA content, external air pressure and holding time of positive pressure mainly dominate the size of formed droplets. Given the properties of materials/solutions for PAM may vary, the adjustment of parameter sets, usually laborious and timeconsuming, was a must to understand the available precision. To save time and energy, the viscosity of SA solutions was measured by a viscometer (Poiylab-RC-300P, Haake Technik GmbH, Germany), and stereomicroscope (XTL-240, Changfang Optical Instrument, China) was used to characterize the droplets.

\subsection{Estimation of droplet size}

To stabilize the control of droplet, it is of great significance to estimate the actual size. Gravimetry is fine for average but not for uniformity, as the mass of a droplet is usually close to the minimum scale (1mg), which would cause error. A useful method for estimation (Fig. 2) was introduced, assuming that the contact angle was equivalent for all droplets under the same condition, regardless of the difference in dimension. In this case, the contact angle can be easily calculated by large droplets with the assistance of TSView software (v7.3, Changfang) (Fig. 2). Then the actual volume can be estimated according to Eq. (I):

$$
\left\{\begin{array}{c}
\mathrm{V}_{\mathrm{d}}=\int_{\mathrm{R}_{\mathrm{h}}}^{\mathrm{R}_{\mathrm{o}}} \pi\left(\mathrm{R}_{\mathrm{o}}{ }^{2}-\mathrm{h}^{2}\right) \cdot \mathrm{dh}(\mathrm{I}) \\
\sin \theta=\frac{\mathrm{R}_{\mathrm{c}}}{\mathrm{R}_{\mathrm{o}}} \\
R_{h}=\sqrt{R_{o}^{2}-R_{c}^{2}}
\end{array}\right.
$$

Where $\mathbf{h}$ is integral height. In view of that $V_{d}$ also equals $\pi \mathbf{d}_{\mathbf{a}} \mathbf{3} / \mathbf{6}$, we can get the relationship of $\mathbf{D}_{\mathbf{a}}$ and $\mathbf{D}_{\mathbf{c}}$ through Eq. (II):

$$
D_{a}=D_{c} \cdot \sqrt[3]{\frac{2-3 \cos \theta+\cos ^{3} \theta}{4 \sin ^{3} \theta}}=F_{c} \cdot D_{c} \text { (II) }
$$

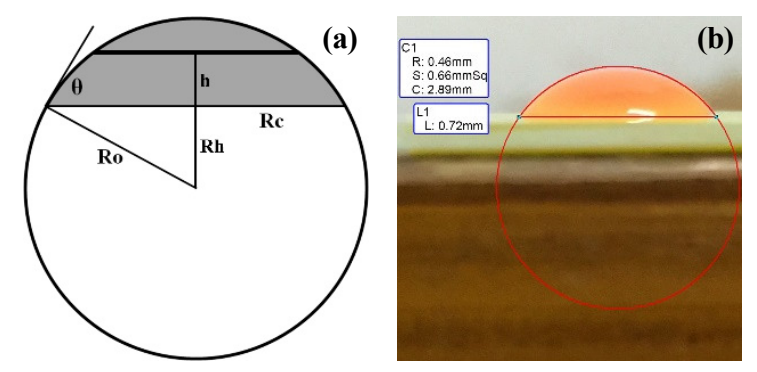

Fig. 2 Estimation method for actual size of droplet. Note for abbreviations in (b): $\mathbf{C 1}$ - circle, $\mathbf{R}$ - radius $\left(=\mathrm{R}_{0}\right), \mathbf{S}$ - area, $\mathbf{C}$ circumference, $\mathbf{L} 1$ - line, $\mathbf{L}$ - length $\left(=\mathrm{D}_{\mathrm{c}}\right)$.

\subsection{Fine control of droplet}

From the point of view of control flow (Fig. 3), accurate control of droplet can hardly be achieved without high response rate. Apart from control center, high response parts were used as the other elements in the flow. For instance, optoelectronic coupling relay (TLP250, Jixiang Electronics, China) can response almost immediately, and the actual responding time $(\sim 0.2 \mathrm{~ms}$ in total, including operation and release) was detected by an oscilloscope (MSOX-2004A, Agilent Technologies,
USA). Besides, high performance solenoid (33 series, Mac Valves, USA) can respond to relay within $1 \mathrm{~ms}$ (energize: $0.5 \mathrm{~ms}$, de-energize: $0.2 \mathrm{~ms}$ ). In addition, the air pressure was controllable at fine precision $( \pm 0.1 \mathrm{kPa}$ ) by regulator (GR200-8, AirTac International Group, China), which greatly facilitates the adjustment of pressure. Another strategy regarding PAM nozzles is hydrophobic treatment with commercially available Teflon solution (DY18/19, Doyo Paint, China), according to the process described in user manual (Fig. 4). The nozzle was initially coated with solution A (DY18), and heated to $150^{\circ} \mathrm{C}$ (holding for $10 \mathrm{~min}$ ) at a rate of $4^{\circ} \mathrm{C} / \mathrm{min}$, followed with cooling inside the furnace (KSL-1700, Kejing Materials Technology, China) to room temperature. The treatment of solution B (DY19) is much similar: coating with B $\rightarrow$ heating to $380^{\circ} \mathrm{C}$ at $4^{\circ} \mathrm{C} / \mathrm{min} \rightarrow$ holding for $10 \mathrm{~min} \rightarrow$ cooling inside furnace.

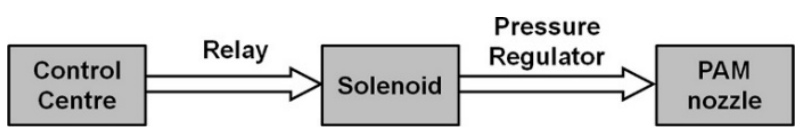

Fig. 3 Control flow of PAM system.

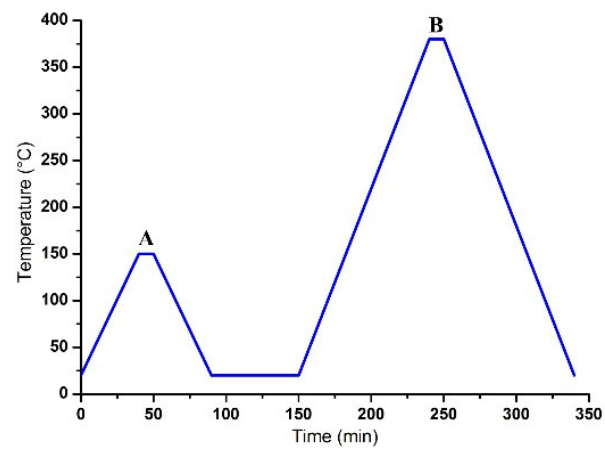

Fig. 4 Hydrophobic treatment of PAM nozzles with Teflon (A-18, B19).

In order to guarantee the stability of PAM, tests based on each SA solution with certain sets of parameters (20 drops for each set) was studied. The standard for stability $(\%)$ here refers to the ability of PAM to successfully form droplets without defects (like satellite drop(s), large accumulation of bubbles in a drop, etc.). Unfortunately, it is hardly likely to ensure $100 \%$ stability due to possible turbulence by air shock at high pressure, so $90 \%$ or more was taken as high stability. Note that droplet size was neglected in practical test. Specifically, once failure in formation of a droplet during PAM jetting was found, the stability would be minused by $20 \%$ to mark such invalidity; similarly, it minus by $5 \%$ once there was-satellite drop(s) or large accumulation ef bubbles in a drep any defect. Failure of formation is mainly because of insufficient air pressure, and the reason of satellite drop was explained by Klüsener $\frac{22}{}$. As for bubble accumulation, it is the usually interactive result of positive air pressure (AP) and holding time (HT) of pressure. The interval of HT was set as $1.5 \mathrm{~ms}$, and AP was increased by $0.1 \mathrm{kPa}$.

\subsection{Improvement of efficiency}

Due to inertia effect, the droplets will be out of control and even severely deformed after in touch with support/substrate, at high travel speed, which may also result in inaccurate positioning. As a result, PAM nozzles would stop for a while ( $\sim 300 \mathrm{~ms})$ during jetting to make sure the velocity in travel direction was almost zero, minimizing the 
impact of speed. However, it would be pretty time-consuming to build $3 \mathrm{D}$ constructs especially in large demand of biomaterials. So it is very important to improve the efficiency of PAM jetting. Provided that the droplets were finely controlled, an easy and efficient way was to decrease the travel times of nozzle. To be more detailed, if the current layer requires PAM jetting frequently, either independent or convergent mode, larger drops with equivalent mass for less times instead of adjacent smaller ones would obviously work (Fig. 5(a)). Accordingly, it had been realized with the design of command order (automatically generated) (Fig. 5(b)). It turned out that this could save about $25 \%$ of total time overall during fabrication.

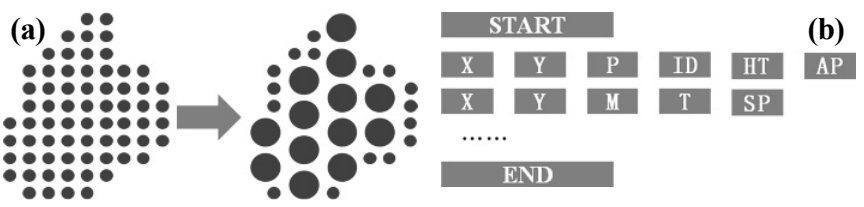

Fig. 5 Schematic of (a) efficiency improvement, and (b) command order. 'X'/'Y' - destination position (mm); 'P' for PAM, 'M' for MAM; for PAM, 'ID' tells the active nozzles, e.g. 1 stands for 'P1', 12 for 'P1+P2' etc.; 'HT' - holding time, 'AP' -air pressure; for MAM, 'T' indicates the compensation of distance between MAM and last PAM nozzle(s), and 'SP' is extrusion speed.

\section{Results and discussion}

\subsection{Precision and stability}

The precision of PAM, or the minimum dimension of stable droplets, was evaluated for all SA solutions, as presented in Fig. 6, which shows the difference before and after hydrophobic treatment of PAM nozzles as well. Obviously, hydrophobic treatment indeed notably reduced the size of minimized droplet $(\geq 20 \%$ ) in all solutions, indicating that hydrophobicity really contributed to improving precision. In addition, precision has close relation to viscosity of SA solutions; specifically, higher precision may be obtained with lower content of SA. Interestingly, it is found that the increase rate of precision by hydrophobicity decreases as viscosity grows. A possible explanation would be: at very low viscosity, surface tension plays the dominant role; while as viscosity increases, the impact of viscosity would be increasingly considerable. Although further study is required to approve this, the influence of viscosity on precision is definite. To make sure the precision of PAM is acceptable $(<1000 \mu \mathrm{m})^{25}{ }^{4}$ and droplets can be easily solidified after printing, our research mainly concentrated on $0.25-1.00$ wt.\% SA solutions. As shown in Fig. 6, the precision in this range shows almost linear change with slight fluctuation. The stability indicates that the estimation of precision at given viscosity is possible and feasible. For instance, presumed that the viscosity of a solution was about $0.06 \mathrm{~Pa} \cdot \mathrm{s}$ (between 0.50 and $0.75 \mathrm{wt} . \%$ ), the estimated precision would be approximately $600 \mu \mathrm{m}$.

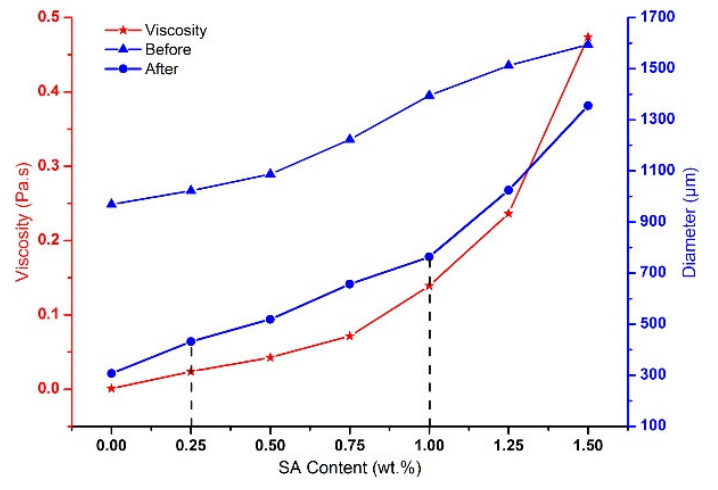

Fig. 6 The relationship of viscosity and minimum diameter before and after hydrophobic treatment.

Fig. 7(a)-(c) shows the optical images, shot at the same magnification and focal distance, of minimum-sized droplets. They were in good conditions and almost perfectly match the measure circles, with great uniformity ( $\geq 98 \%$ ) in terms of cross-diameter ( $\left.D_{c}\right)$. Fig. $7(d)$ is for evaluation of stability and positioning accuracy with 10 droplets at a distance of $2 \mathrm{~mm}$. The result is satisfying in terms of stability and uniformity, as well as the accuracy in positioning. In other words, the PAM system can be well controlled to get droplets with fine precision.
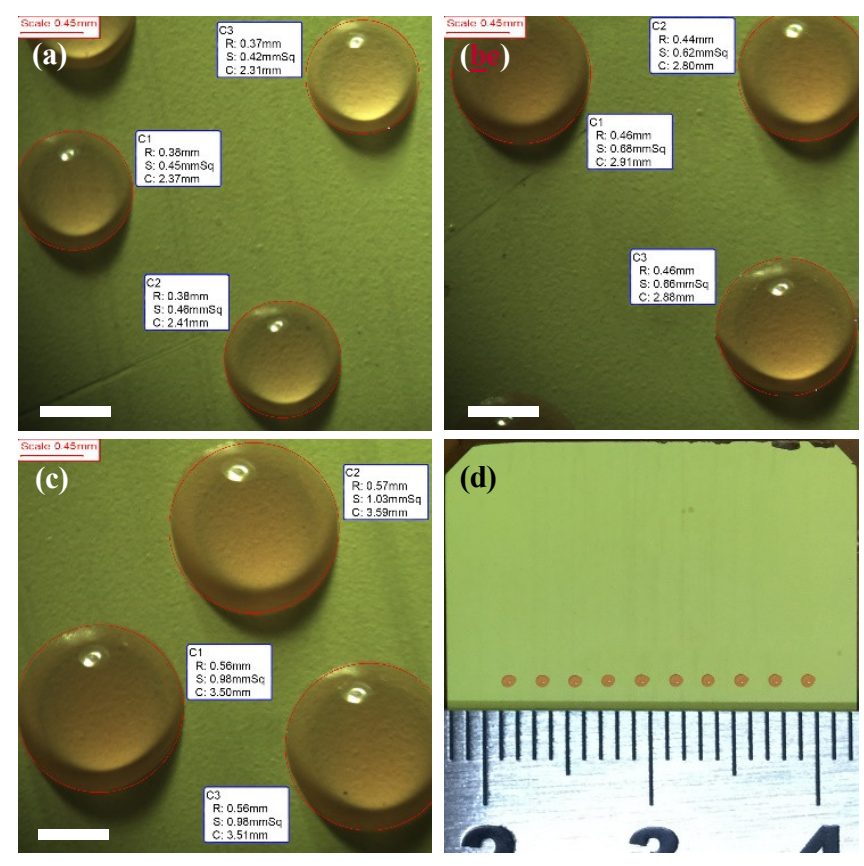

Fig. 7 Optical images of droplets: (a) $\mathrm{D}_{\text {avg }}=432 \mu \mathrm{m}(0.25 \mathrm{wt} \% \mathrm{SA}, \theta=$ $\left.50.4^{\circ}, \mathrm{F}_{\mathrm{c}}=0.574\right)$, (b) $\mathrm{D}_{\mathrm{avg}}=519 \mu \mathrm{m}\left(0.50 \mathrm{wt} \% \mathrm{SA}, \theta=51.1^{\circ}, \mathrm{F}_{\mathrm{c}}=\right.$ $0.578)$, (c) $\mathrm{D}_{\mathrm{avg}}=657 \mu \mathrm{m}\left(0.75 \mathrm{wt} \% \mathrm{SA}, \theta=52.3^{\circ}, \mathrm{F}_{\mathrm{c}}=0.583\right)\left(\mathrm{D}_{\mathrm{avg}}\right.$ stands for average of $\mathrm{D}_{\mathrm{a}}$ ) (scale bar $\left.=500 \mu \mathrm{m}\right)$; (d) evaluation of stability $(0.50 \mathrm{wt} . \% \mathrm{SA})$ and precision in positioning.

Table $\amalg \underline{2}$ shows the favorable AP and HT sets for high stability $(\geq$ $90 \%$ ) in all SA solutions. It was found that the value of AP and HT would increase as more SA was contented. This is reasonable in the light of energy conservation, since more energy would be consumed by frictional resistance, due to rising viscosity in drop formation. An sample result of stability test at $0.50 \mathrm{wt} . \%$ was shown in Fig. 8 . The result reveals that higher HT preferred lower AP to make ejection reliable, which is very useful for parameter adjustment in future. It is similar in other SA solutions. 
Table $\amalg \underline{2}$ Favorable AP, NP and HT sets for high stability

\begin{tabular}{llll}
\hline SA (wt.\%) & AP $(\mathrm{kPa})$ & HT $(\mathrm{ms})$ & $\mathrm{NP}(\mathrm{kPa})$ \\
\hline 0.25 & $15.0 \sim 35.0$ & $3.0,4.5$ & 3.3 \\
0.50 & $25.0 \sim 35.0$ & $3.0,4.5,6.0$ & 1.8 \\
0.75 & $25.0 \sim 40.0$ & $4.5,6.0$ & 0.7 \\
1.00 & $35.0 \sim 45.0$ & $4.5,6.0$ & Not necessary \\
\hline
\end{tabular}

NP: negative pressure.

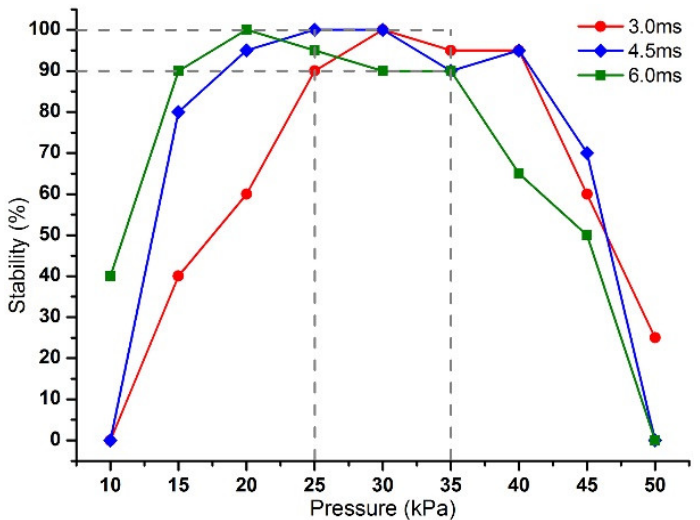

Fig. 8 The sample relationship of droplet stability with AP and HT.

As mentioned before, minimum-sized droplets are not always demanded in consideration of efficiency. Generally, it is very difficult to achieve the exact size by merely adjusting SA content, AP and HT, so $50 \mu \mathrm{m}$ was set as increment based on minimum size. The result of was summarized in Fig. 9 (10 drops for each set). Overall, the droplets present good uniformity ( $\geq 95 \%$ ), despite that the deviation actually shows rising trend when SA content increases. The parameter sets for every dimension were on the basis of Table $2 \mathbb{H}$ to ensure stability. A database according to this result had been set up to accelerate the adjustment of parameters. For a solution with given viscosity, the database can offer reference for the suitable set of HT, AP and NP to achieve desired size of droplets with great convenience. For example, if $600 \mu \mathrm{m}$ was wanted from $0.40 \mathrm{wt} . \%$ SA solution, the suggested set of HT, AP and NP would be $3.0 \mathrm{~ms}, 27.8-34.4 \mathrm{kPa}$, and $1.8-3.3 \mathrm{kPa}$ respectively. In addition, for droplets smaller than $\mathrm{S} \Phi 650 \mu \mathrm{m}, 3.0 \mathrm{~ms}$ is enough for HT, and $35.0 \mathrm{kPa}$ may be the up limit of AP. Similarly, for those within S $\Phi 700-800 \mu \mathrm{m}$, HT should better be $4.5 \mathrm{~ms}$, and AP must be higher than $25.0 \mathrm{kPa}$. The list goes on like this. All in all, the amount of work to adjust parameter sets for new materials/solutions will be greatly reduced.

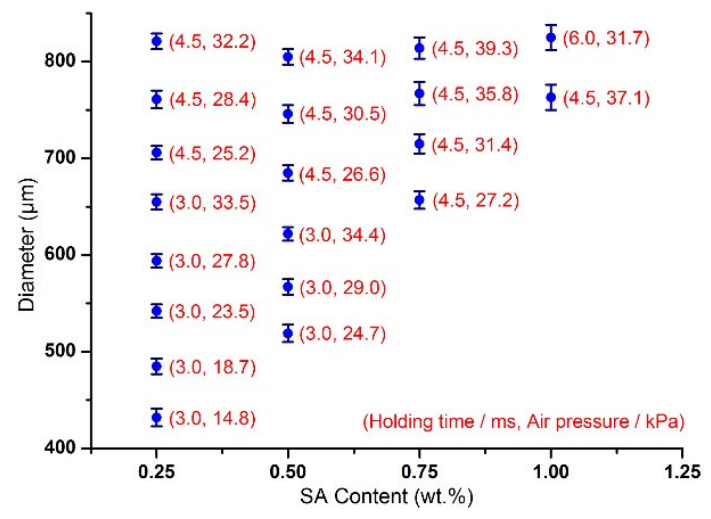

Fig. 9 Parameter sets for certain sized droplets.

\subsection{Coordination and synchronization}

The key challenge for PAM-MAM (multi-nozzles) system lies in their coordination and synchronization, especially in independent and convergent mode. Therefore, experiments using 0.50wt.\% SA solution for PAM jetting were carefully designed to confirm this. The dot matrix in Fig. 10(a) was primarily to evaluate the repeatability and accuracy of positioning, in which the droplets could manage to keep good shape and maintain accurate location. On the other hand, "HUST" in Fig. 10 (b) is another expressive example. "H", and "S"-and "T" were printed by PAM at highest precision $\left(\mathrm{D}_{\mathrm{a}}=-487- \pm-26 \mu \mathrm{m}\right)$ in independent mode; while "T" was formed in convergent mode, reasonably resulting in larger and less regular droplets $\left(D_{a}=\sim 676- \pm\right.$ $53 \mu \mathrm{m})$ due to impaction and adhesion of droplets. It shows that the precision both in size and positioning is acceptable, greatly owing to the set of convergent focus on substrate, short pause and low frequency during jetting. Although the satellite drops caused by collision were unavoidable, it affected the precision only a bit $(<5 \mu \mathrm{m})$. It is worth mentioning that the droplets assembling "H" were actually blue, which yet looks green due to color overlay (blue plus yellow will be green); similarly, "S" appears orange instead of red, and "T" is dark rather than purple. In summary, PAM-MAM could keep fine precision as well as good coordination and synchronization during work, providing the essential foundation for fabricating 3D complex scaffolds with multibiomaterials.
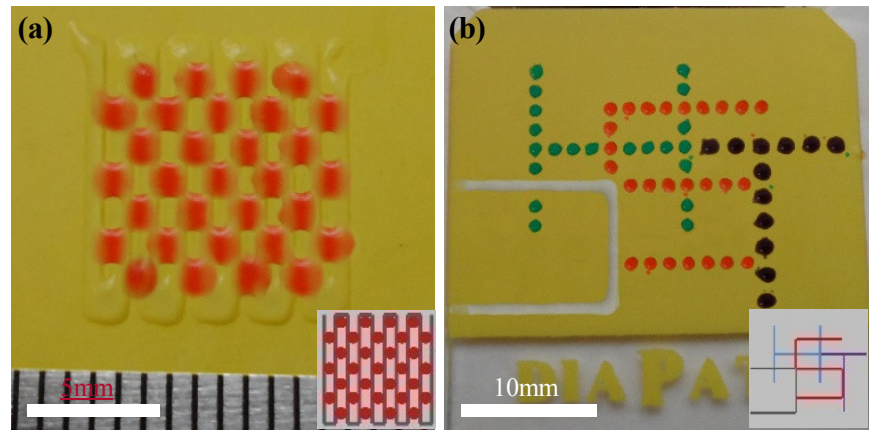

Fig. 10 Patterns for evaluation of coordination: (a) dot matrix, and (b) "HUST" ('H' by P1, 'U' by M4, 'S' by $\mathbf{P 3}$, and 'T' by $\mathbf{P 1 + P 3 ) . ~ T h e ~}$ figure in right corner is the original design of each pattern.

\subsection{Potential application}

In our recent research, biomimetic scaffolds with multi-biomaterials (e.g. collagen) for repair of the cranium defect (rabbit) showed absolute advantages to normal scaffolds made by MAM. The result has been processed for publication elsewhere. Fig. 11 shows the 3D model with SA solution (0.5wt.\% for PAM, and $10.0 \mathrm{wt} . \%$ for MAM) for demonstration; while actually it was composed of biomaterials (jetting by PAM) and matrix (extrusion with MAM) with SA as solidification agent in practice. The sample has 6 layers in total: the 1 st and 6th layer in transparency stands for antimicrobial materials; and the 2nd and 5th layer in green with porous structures were designed for collagen filling; the middle two layers with dual red lines which consists of droplets represent biological factors. It is worth mentioning that the desired size of droplets for this scaffold should be about $500 \mu \mathrm{m}$; however, to improve efficiency, the jetting strategy in Fig. 5(a) was adopted, resulting in two lines rather than dot matrixes. After quick solidification (cross-linking reaction) with calcium chloride solution, 
the droplets were able to keep original shape, and could be well supported by porous scaffold due to good strength, shown in Fig. 11(b). It indicates that PAM-MAM is competent to make 3D biomimetic scaffolds in terms of materials and structures, exhibiting great potential to tissue engineering.
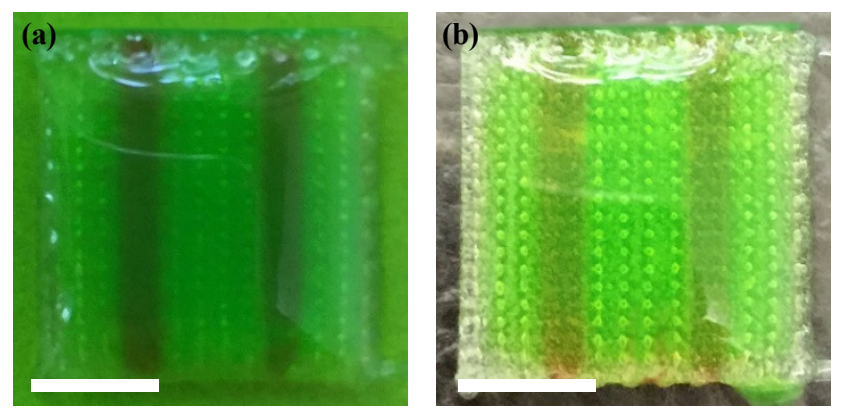

Fig. 11 3D model of biomimetic scaffolds for repair of rabbit cranium defects, (a) before and (b) $12 \mathrm{~h}$ after solidification. Scale bar $=5 \mathrm{~mm}$.

\section{Conclusions}

In this study, a newly combined multi-nozzle system based on MAM and PAM was introduced. The influence of AP, HT and SA content on droplet size and stability was investigated in details. The results show that droplets by PAM jetting can be finely controlled with good precision $(\sim S \Phi 430 \mu \mathrm{m})$ and high stability $(\geq 90 \%)$. The parameter sets for certain size can be easily obtained with the assistance of our database, regardless of the various properties of materials for PAM. The most of all, this system can deal with materials both of low and high viscosity with satisfying coordination and synchronization, making it highly potential to fabricate 3D complex scaffolds with multi-biomaterials and sufficient strength for tissue engineering. Thus it is highly expected that this research could provide practical and technical reference for the development of organ printing.

\section{ACKNOWLEDGEMENT}

This study was fully supported by the project from State Key Lab of Materials Processing and Die \& Mould Technology (No.2014-5), and partially funded by programmes from Science and Technology Support Program of Jiangsu (No.BE2013057). The authors would also like to acknowledge The rheology test of SA solution was performed at the Analytical and Testing Centre of Huazhong University of Science and Technology for rheology test of SA solution.

\section{REFERENCES}

[1]). Ringeisen, B. R., Spargo, B. J., and Wu, P. K., "'-“Cell and organ printing,"', Springer Sci.ence \& Bus.iness Media, 2010.

¡2\}2. Yoo, D. J.2 "“"Recent trends and challenges in computer-aided design of additive manufacturing-based biomimetic scaffolds and bioartificial organs, " $"$, Int_ernational J.eurnal of-Precis_ion Eng.ineering and-Man_ufacturing, Vol. 15, No. 10, pp. 2205-2217, 2014.

Ł3]). Gibson, I., Rosen, D.W.-5 and Stucker, B., "- "AAdditive manufacturing technologies, ${ }^{\prime \prime}$, Vol. 238, New York: Springer, Vol. 238 , 2010.

[4]). Wong, K. V.-; and Hernandez, A.2 "-A review of additive manufacturing",", ISRN Mech_anical Eng.ineering, Vol. 2012, 2012.
[5]). Guo, N.-, and Leu, M. C. ." _-Additive manufacturing: technology, applications and research needs", "- Front_iers of Mech_anical Eng.ineering, Vol. 8, No. 3, pp. 215-243, 2013.

[6]). Bose, S., Vahabzadeh, S.; and Bandyopadhyay, A., "-"Bone tissue engineering using 3D printing",", Materials. Today, Vol. 16, No. 12, pp. 496-504, 2013.

[7]). Chern, M. J., Yang, L. Y., Shen, Y. K.; and Hung, J. H., “"-3D scaffold with PCL combined biomedical ceramic materials for bone tissue regeneration",,’ Int.ernational J.eurnal of Precis.ion Eng.ineering and Man.ufacturing, Vol. 14, No. 12, pp. 2201-2207, 2013.

[8]2. Pati, F., Song, T. H., Rijal, G., Jang, J., Kim, S. W.-, and Cho, D. W.. "-"Ornamenting 3D printed scaffolds with cell-laid extracellular matrix for bone tissue regeneration",," Biomaterials, Vol. 37, pp. 230 $241,2015$.

¡9]). Suárez-González, D., Lee, J. S., Diggs, A., Lu, Y., Nemke, B., Markel, M., Hollister, S. J.; and Murphy, W. L. ${ }_{2}$ "-Controlled multiple growth factor delivery from bone tissue engineering scaffolds via designed affinity",," Tissue Eng.ineering Part A, Vol. 20, No. 15-16, pp. 2077-2087, 2013.

¡10]). Klein, T. J., Rizzi, S. C., Reichert, J. C., Georgi, N., Malda, J., Schuurman, W., Crawford, R. W., and Hutmacher, D. W.. "-"Strategies for zonal cartilage repair using hydrogels", " Macromol_ecular Biosci_ence, Vol. 9, No. 11, pp. 1049-1058, 2009.

Ł11\}). Chang, L., Thian, E., Sun, J., Fuh, J., Hong, G., Wong, Y.; and Wang, W.2 "Fabrication of functionally graded Hydroxyapatitehydroxyapatite /_T Titanium Oxide oxide Coating coating via Đropdrop-on-Đemand-demand Techniquetechnique", " Nano LIFE, Vol. 2, No. 01, pp. 1250009, 2012.

[12]). Lee, J. S., Hong, J. M., Jung, J. W., Shim, J. H., Oh, J. H., and Cho, D. W.. "-" $3 \mathrm{D}$ printing of composite tissue with complex shape applied to ear regeneration",," Biofabrication, Vol. 6, No. 2, pp. 024103, 2014.

[13]). Kalita, S. J., Bose, S., Hosick, H. L.; and Bandyopadhyay, A., "-Development of controlled porosity polymer-ceramic composite scaffolds via fused deposition modeling",," Mater.ials Sci_ence and Eng.ineering: C, Vol. 23, No. 5, pp. 611-620, 2003.

¡14ł). Williams, J. M., Adewunmi, A., Schek, R. M., Flanagan, C. L., Krebsbach, P. H., Feinberg, S. E., Hollister, S. J., and Das, S.. "-"Bone tissue engineering using polycaprolactone scaffolds fabricated via selective laser sintering",", Biomaterials, Vol. 26, No. 23, pp. $4817-$ 4827, 2005.

¡15ł). Singh, M., Haverinen, H. M., Dhagat, P.; and Jabbour, G. E., "-Inkjet printing____ process and its applications"," Adv_anced Mmater.ials, Vol. 22, No. 6, pp. 673-685, 2010.

[16]). Schiele, N. R., Corr, D. T., Huang, Y., Raof, N. A., Xie, Y.; and Chrisey, D. B., "-Laser-based direct-write techniques for cell printing",," Biofabrication, Vol. 2, No. 3, pp. 032001, 2010.

Ł17f). Huang, W., Zhang, X., Wu, Q., and Wu, B., "-Fabrication of HA/ $\beta$-TCP scaffolds based on micro-syringe extrusion system", " Rapid Prototyping J.eurnal, Vol. 19, No. 5, pp. 319-326, 2013.

[18\}). Ren, X., Zhang, Q., Liu, K., Li, H.-L.; and Zhou, J. G., "-Modeling of pneumatic valve dispenser for printing viscous biomaterials in additive manufacturing",,' Rapid Prototyping J_eurnal, Vol. 20, No. 6, pp. 434-443, 2014.

[19]). Blandino, A., Macias, M.- and Cantero, D.2 "-"Formation of calcium alginate gel capsules: influence of sodium alginate and $\mathrm{CaCl}-2$ concentration on gelation kinetics",," J.eurnal of biescience-Biosci. and bioengineeringBioeng., Vol. 88, No. 6, pp. 686-689, 1999.

20) Zactiti, E. M. and Kieckbusch, T. G., "Release of potassium sorbate 
from active films of sodium alginate crosslinked with calcium chloride," Packag. Technol. Sci., Vol. 22, pp. 349-358, 2009.

[210]). Zhou, K., Zhang, X., Chen, Z., Shi, L.; and Li, W., "-Preparation and characterization of hydroxyapatite-_sodium alginate scaffolds by extrusion freeforming",," Ceram_ics Int_ernational, Vol. 41, No. 10, pp. 14029-14034, 2015.

[221]). Klüsener, O.. _-"The injection process in compressorless diesel engines",", VDI Z, Vol. 77, No. 7, 1933.

\{2를). Ohnesorge, W. V., "'-Formation of drops by nozzles and the breakup of liquid jets",," Z. Angew. Math. Mech., Vol. 16, No. 4, pp. 355-358, 1936.

[2437). Lefebvre, A. "“-Atomization and sprays",", CRC press, 1988.

\{254]). Yeong, W. Y., Chua, C. K., Leong, K. F.; and Chandrasekaran, M.2 "-"Rapid prototyping in tissue engineering: challenges and potential",", Trends in Biotechnol.biotechnology, Vol. 22, No. 12, pp. 643-652, 2004. 